\title{
ESCOLIOSIS PLEURITICAS
}

\author{
Por el Dr. LUIS BISQUERTT S.
}

Cirujano del Hospital de Niños "Manael Arriarán"

Prolesor de Kinesiterapia del Instituto de Educación Fisica de la U. de Chite.

El haber visto últimamente algunos casos de escoliosis de origen pleural. nos ha inducido a hacer algunas consideraciones sobre este tipo de deformación tóraco-raquídea. Hemos buscado literatura al respelto: pero, ya sea porque la hay muy escasa, o por 'as dificultaces de la búsqueda, sólo hemos encontrado el trabajo de Seth Selig y Ennest Arnheim en los "Archives of Surgery" del noviembre de 1939, intitulado Scoliosis following empyema" y se refiere a observaciones de 65 casos de empiemas no tuberculosos operados en el. Mount Sinai Hospital de New York.

Entre 340 casos de escoliosis reunidos en la Sección de Kinelsiterapia del Instituto de Educación Física y el Servicio de Cirugía y Ortopedia del Hospital Arriarán (309 casos en el Instituto de Educación Física y 31 en el Hospital Arriarán) en el lapso de 1930 a 1941, hemos encontrado 11 casos. ce escoliosis de etiopatogenia pleural, en niños y adolescentes, cuỳa época de aparición de la escoliosis fluctúa entre los 3 y los 20 años. Ocho de élos corresponden a empiemas a neunococos; uno a empiema a estreptococos por complicación de an pneumotórax terapéutico; uno a tuberculosis pleuro-palmonar y el otro a quiste hidatídico abierto a la pleura y vaciaso por pleurotomía. En esos mismos 11 años se han operado en el Servicio de Cirugía del Hospital Arriarán 387 empiemas, habiendo quedado con secuela escoliótica 4 casos comprobados, sin que pueda asegurarse que no se hayan pret. sentado otros en niños operados que no hayan śido examinados más tarde. 
En el Instituto de Educación Física se han tratado en los últimos once años $(1930-1941) 309$ casos de escoliosis (101 hombres y 208 mujeres), encontrándose 4 casos de escoliosis de origen pleural: 3 hombres, 1 mujer.

Según los datos anteriores, el $3,23 \%$ de las escoliosis corresponde entre nosotros, a deformaciones tóraco-raquídeas de etiopatogenia pleural y el $1.03 \%$ por lo menos de los empiemas pleurales operados dejan retracción torácica y escoliosis. Decimos "por lo menos". potque no hemos controlado postelriormente todos los casos de empiemas operados en el hospital. Sin embargo, esa cifra debe estar muy cerca če la realidad. pues la deformación aparece generalmente desde un principio, durante el período supurativo, cuando los niños estản aún hospitalizados o controlados en policlín co, o sea. en el setrvicio de consulta externa.

Estudiando las deformaciones en los casos que nos ha tocado ver. hemos creido poder precisar las caracteristicas de ese tipo de escoliosis. que exponemos a continuación.

Características de las escoliosis de cansa plenral.

Analizando los once casos examinados, creemos poder establecer las siguientes características:

1. Curvadura dorsal principal de concavidad hacia el Iado de la Jesión.

En los once casos por nosotros observados, la escoliosis presenta su concavidad hacia el lado de la lesión, siendo siempre dorsal la curvadura principal, $y$ cérvico-dorsales o dorsolumbares las curvaduras de compensación, cuando las hay. Creemos que siempre debe ser así. ya que la retracción cicatricial, la sinfisis pleural, tiende a disminuir el tamaño y la capacidad del hemitórax afectado, acercando las costillas y traccionándolas hacia adentro, ayudado todo esto por la actitud en flexión lateral en quet se inmoviliza el niño que sufre te un proceso supurado crónico pleural. Para Selig y Arnhe m existen escoliosis pleuríticas de curvadura inversa, es decir, de converxidad hacia el lado de la lesión, las que sólo se presentarían en los sujetos sometidos a toracoplastías. Hacemos presente, de todos modos, que no nos ha tocado ver sino una de estas escoliosis consecutivas a toracoplastias, entre las cuales estarian las escoliosis inversas de los autores norteamericancs. Estas presentarían su convexidad hacia el lado de las 
costillas resecadas, neutralizando o sobrepasando la primitiva curvatura, cóncava hacia la lesión.

\subsection{Mayor rigldez.}

Hacemos notar que las escoliosis pleuríticas presentan una rigidel marcadamente mayor que la de las escolios:s de otra etiología, por lo menos en el prímer. período. La inmovilidad prolongada en actitud viciosa, por una parte; el proceso cicatricial intenso, por la otra, han disminuíjo la elasticidad músculo-ligamentosa tóraco-raquídea hasta llegar a veces a presentarse el tronco como un solo bloque.

\subsection{Precedencia de la asimetria toricica.}

La asimetría torácica precede a la inflección latera!, provocándola, al contratio de lo que ocurre en las escoliosis cotrientes, que comienzan por la inflezción lateral. siguiéndose Ja rotación vertebral con la asimetria consiguiente. Este hecho se explica porque a causa de la deformación es intratorácica y no vertebral o muscular como en las otras categorías de escoliosis.

\subsection{Menor rotación vertebrai.}

Si comparamos jos escol osis con el mismo grado de deformación, una pleurítica y la otra nó, la escoliosis pleurítica. no nos presentará rotación vertebral o nos la presentará en un grado muchísimo menor, lo que está en relación también con el origen torácico y no vertebral de la deformación. Este nos expliza también el menor grado de deformación del cuer po vertebral, ya que no obrando como causa primera y esencial la estática, en otras palabras, la desigualdad de presión sobre los cuerpos vertebrales, no tiene lugar a cumplirse la ley de Dolpech. como en los otros tipos de escoliosis. Esta ley establece que los huesos crecen más en las zonas que no reciben las presiones habituales, monos en las zonas de mayor presión. produciéndose un desequilibrio en su forma como resultado de tal-alteración estática.

\section{Asimetria torácica por disminución volumétrica del hemitórax afectado.}

La asimetría torácica en las escoliosis plefuriticas responJe siempre al típo de disminución volumétrica del lado afectado respecto del otro. Es decir, el perímetto exteitno del bemitórax afectado es menor, sin que aparezca el solevan- 
tamiento condrocostal antetrior, típico de las escoliosis con rotación vertebral, no pieuríticas. En las pleuríticas aparece, en vez de ese solevantamiento, una depresión que puede extenderse a toda la cara anterior del hemitórax y que es mayor o menor según el grado de la retracción cicatricial pleural.

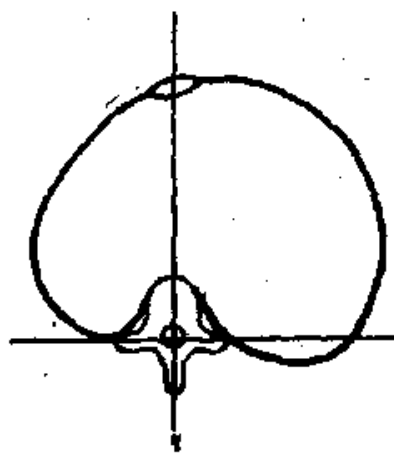

Fig. 1
Fig. 2.

Exquema de an cortie de tórax típico Esquêma de un corte de tórax en una de una escoliosis pleuritica. escoliosis e:encial con rotación vertebral:

\section{MEDICION}

Para dejar constancia del estado de la deformación. practicamos una medición lo más precisa posible. Para esto podríamos servirnos de los aparatos ce Schu'tess, el gran ortopedista suizo que tanto estudió en su clínica de Zurich el problema de las desviaciones raquídeas, pero como es difícil y dispendioso disponer de estos medios, podremos contentarnos con un simple hilo a plomo. Para obtenet la madida gráfica del perímetro torácico a nivel de la mayor deformación. podemos servirnos del toracómetro de Démeny (Fig. 3), que nos permite apreciar la asimetría y el valor relativo de ambos hemitórax, ya sea en inspiración media. en expiración o en inspitación profunda. En cuanto a la meldición de la capaciead vital mediante la espirometría, le atribuímos poca importancia, y en los niños menores de 10 años, casi ninguna. Nunca estamos seguros de que efectúan antel nuestro reque rimiento upa inspiración o expiración máximas, con mayor razón si alguna dificultad en la movilidad torácica les perturba. Por otra parte, piérdese demasiado tiempo en solicitaciones y explicaciones. Asi, pues, sólo en a'gunos casos la empleamos. 
Re:Decto al criterio con que, a nuestro juicio, debe apreciarse el g:ado o intensidad de la escoliosis. hatemos una aclaración.

Nos parece engañoso y poco lógico el procedimiento emplezdo por los autores norteamericanos citados. al calificar la intensidad de la escoliosis según el grado del ángulo de la curvadura. Miden el ángulo y dicen sencillamente, por ejemplo: escoliosis de $40^{\circ}$. Sin etmbargo, ese ángulo no puede traducir la mayor o menor intensidad de las deformaciones que en la escoliosis afectan no sólo al raquis. sino al tórax y al

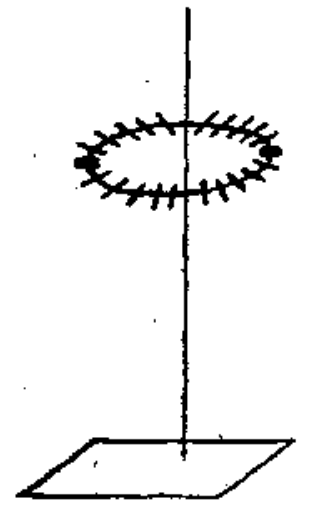

Esquema del toracómetro
de Demeny, aparato que
nos permite tomar gráfices
del perimetro. torático, ya
sea en inspiración, expira
ción o inspiración media,
como las que presentamos
tás adelante que nos
sirvin de medidas de con-
trol.

tronco en general. Dos escoliosis con un ángulo igual puedeln, a pesar de eso, presentar un distinto grado de evo'ución y deformaciones de muy diferente intensidad. Una puede estar estáticamente desequilibrada y la otra no, como puecét verse en la Fig. $\triangle$ y $B$. En $A$ hay desequilibrio estático y mayor deformación, a pesar de tratarsø de más o menos la misma angulación que la de la fig. B. Con el procedimiento de los autores norteamericanos, ambas escoliosis se equivalen, lo quel no está acorde con la realidad.

Nosottos preferimos, al medir una escoliosis, valernos. de la vertical que pasa por la extremidad superior del plegue interglúteo, suponiéndo el piso horizontal y longitud igual en ambos miembros inferiores, la que ha sido previamente verificada. Figs. 4 y 5.

De esta manera, diremos que la escoliosis teme una desviación igual a la distancia que hay entre esta vertical (representada por un vástago metálico o sencillamente por un hilo a plomo) y el panto más alejacio de la curva raquídea. No tomamos como punto de referencia la apófisis espinosa de la $7 .{ }^{\circ}$ cervical, porque se trata del un punto variable, inseguro. 
cuya abicación en el espacio puede ser patológica, si se nos permite la expresión. Decimos esto porque la ubicación de ese punto está determinada por los caracteres de la deformación. Iuego, no puede servirnos como punto de referencia para medir esa misma deformación. En cambio, el punto que representa la extremidad superior del pliegue interglúteo es fijo, normal, si as pudiéramos decir, y no está influenciada su ubicación en el espacio por la deformación escoliótica.

Si medimos con este procedimiento las escoliosis representadas en las figs. A. y B, encontraremos que, a pesar de tener el mismo ángulo; la escoliosis de $A$ es mayor que la de $\mathrm{B}$, lo que sí que está de acuerdo con la realidad. Por otra parte, la distancia entre la misma vettical. y la apófisis espinosa de la 7.* cervical, nos dará el grado de desequilibrio, ya sea hacia la derecha o hacia la izquienda.

Dejamos constancia también de la formación con fotografías de espaldas, de frente y de perfil, en posición de pie. indicando con un jápiz dermográfico las apófisis espinosas a partir de la séptima cervical o prominente, el borde interno bel omóplato, su ángulo inferior y su espina. En cuanto a la radiografia, nos interesa especialmente la frontal y estimamos que debe ser tomada de pie, con los talones juntos, las rodillas extendidas y en placa grande, en la que aparezea todo el raquis, a partir de la primera sacra, que sirve de asiento a la columna lumbar y que debe aparecer en la placa. Sólo en esta forma tendremos un punto de partida precico para comparaciones posteriores.

\section{TRATAMIENTO}

Podemos considerar el tratamiento de las escoliosis pleuríticas bajo el aspecto preventivo y bajo el aspecto curativo.

\section{l.er Caso: Tratamiento preventivo.}

Siendo más fácil prevenir la deformación que corregirla una vez producida, conviene pensar en ella en todos los casos de empiemias de evolución larga. En todo empiema cuya evolución sobrepasel un mes de duración y en el que se ñote la tendercia a la rigidez costovertebral y a la actitud viciosa. debemos, sjempre que el estudio de la afección lo permita, movilizar suavel y pasivamente la columna, buscando dar al pequeño enfermo una posición inversa a su actitud viciosa. Utilizaremos algunos ejercicios respiratorios para ampliar el 
hemitórax afectado, sirviéndonos de espirómetros, de veljigas de caucho (bladers), de cornetas. de globos para inflar o del procedimiento de la botella o de Pescher. Si las circunstancias 10 permiten y lo requieren, confeccionaremos un lecho de yeso en posición corregida a fin de que el enfermito repose en él el mayor tiempo posible.

Tan pronto como se pueda, iniciaremos la gimnasia general y ortopédica activa y con movimientos pasivos correctivos y modelantes. No siempre es preciso para esto que la fiebre haya desaparecido, o que la fístula haya cerrado.

En cuanto a la duración de la sesión de éjercicio. el námero de sesione's por día y la intensidad de los ejercicios, son cosas que el mismo estado y resistencia del paciente nos irá indicando.

\section{Caso: Tratamiento curativo.}

Consideramos el tratamiento bajo el punto de vista curativo cuando la afección pleural ha sanado y nos encontramos ante las deformaciones establecidas y permanentes, con el carácter de secuelas. En tal caso - y siempre en rellación con el grado de las alteraciones anatómicas y el tiempo transcurrido- será bien difícil, si no imposible: obtener la desaparición de las deformidades torácicas o raquídeas. Sin embargo siempre hay posibilidad, aun en casos avanzados, de enderezar parcialmente la delsviación y ampliar, en la misma forma, el hemitórax afectado. Siempre obtuvimos una mayor flexibilidad raquídea, quitando al niño la actitud fija de su tronco, que aparenta a vecels estar constituido de una sola pieza, como si todas sus vértebras estuviesen soldadas formando an solo bloque. En tales casos hemos logrado dar bastante movilidad al tronco y hacer la marcha liviana y natural. Hemos conseguido también una mayor amplitud de los movimientos respiratorios, un fortalecimiento evidente de la musculatura del tronco, lo que hace contraste con la lenta convalecencia de los niños no sometidos a una cura gimnástica regular y progresiva.

Estimamos que el tratamiento de estas delformaciones tóraco-raquídeas consecutivas a procesos pleurales crónicos debe ser fundamentalmente kinésico, ayudado por elnyesados modelantes (lechos, corsets) y corsets amovibles en cuero $y$ metal.

Largo sería detallar la técnica del tratamiento kinésico, tratamiento que se confundiria en gran parte con la cura gim- 
nástica de las escoliosis en general. Nos limitaremos a indicar que aconsejamos de prefelrencia ejercicios respiratorios, con ampliación dèl hemitórax afectado; suspensiones asimétricas con oscilàciones de diverso tipo, ya en la barra sueca o en las argollas; marcha de Klapp; reptación en diferentes formas. rorrecciones activo-pasivas partiendo de la posición de rodillas con flexión del tronco adelante, con o sin apoyo de las manos; correcciones pasivas manuales modelantes etn diverisas posiciones en el plint. utilizando sobre todo la posición a horcajadas y los decúbitos avanzados (1). Aparte de esto, ejercicios simétricos de flexibilización del raquis; ejercicios en aparatos Zander, si se dispone de ellos, y ejercicios de gimnasia general de desarrollo de acueirdo con los printipios fundamentales de la escuela escandinava.

No ocultaremos los grandes escollos técnicos que existen para luchar, por medio de ejercicios respiratorios localizados. contra la retracción de un hemitórax. Por mucho que sea el empeño que el kinesiólogo ponga en facilitar la expansión del hemitórax afectado $\mathrm{y}$ en entorpecer con compresiones, actitudes o movimientos, la del hemitórax opuesto, éste logra siempret expandirse, fácil o difícilmente, tendiendo a desarrollarse más que el otro, puesto que. no sólo nada se lo impide, sino que, por el contrario, el pulmón de ese lado busca una hiperfunción compensadora. Por eso, en los casos de retraeciones cicatriciales muy firmes como en los casos $N^{2} 3$ ó $N{ }^{\circ} 6$, si bien bien es cierto que la funçión respirator a mejora notablemente con ell ejercicio extendiéndose el campo de la hematosis, también es cierto que el desequilibrio volumétrico entre ambos hemitórax se hace más marcado. Hemos idelado recientemente, para paliar en parte estas dificultades, un "hemicorsett" en cuero y metal, moldeado exaçtamente sobre el hemitórax sano, en inspiración media, pasando sobre el hombro y llegando por abajo hasta el pelvis, como un corset ortopédico corriente. De esta manera queda limitasa, en mayor o menor grado, la expansión del hemitórax sano du-

(1) Llamamas decúbitos avianzados en gimnasia médica a aquellos dacú. bitos efectnados sobre un flint, o simplemente una mesa, quedando el troncis fuera de él. as decir, en lucha contra la gravedad y las extremidadis inferiore sostenidas medrante apoyo rivo o mediante correas que las atan al plint o a la mesa. Esta posición, a mas del trabajo intenso que puede imponer a la musculatora dorsal, hateral decceba, lateral izquierda o propiamente abdominal, se. gitn que el decúbito sea abdominat, latetal izquiexdo, lateral derecho o dorsal, sacesivamente, permite fáciimente morimientos correctivos manuales del tronco. 
rante la inspiración, gracias al corset, inextensible y más o menos ajustado. Esto obliga a que la necesidad inspitatoria solicite con mayor intensidad la. expansión del hemitórax afectado, ya que ol otro hemitórax está entrabado en cu acción compensadora por el hemicorset. Podemos así reemplazar. en forma más completa y eficaz, las compresiones manuales sobre ell hemitórax sano, durante la lectión de ejercicio.

Es indudable que para imponer en las escoliosis pleuriticas un tratamiento eficaz, se necesita de un local para gimnasia debidamentel equipado, del que ningún hospital ce riños debera carecer, y sobre todo, de personal especializado en gimnasia terapéutica, con buenas bases de gimnasia educativa.

Por último baremos notar que, requiriendo este tipo de afecciones de un tratamiento pacientes y prolongado, a menudo dispendioso, los niños -los del pueblo especialmenteno son llevados a las lecciones de gimnasia con la freliencia necesaria y terminan muchas veces por abandonar la cura antes que ésta rinda el máximum. pudiendo, además, con esto reagravarse las deformaciones, como ocurrió en el caso N."9.

CASO 1. - C. C., 9 años, mujer.

Nacida normalmente y sin antecedentes de importancia hasta lö 7 años. cpoća en que aparece un compiejo primatio. Mejora al cabo de alganos meses de tratamiento adecuado, incluída cura climatérica de altura. En agosto de 1938, grippe que dura algunos dias, repitiéndose al cabo de una sernana, seguita esta vez de neumonía dereha y luega una pleuresia puratenta a prentmococos que. dispnés de uma punción, obliga a unz pleurotomía con tesección costal el 21 de setiembri de ese año. Deñ en abundantia durante 42 diss. tertacdo la herida despnés de los 50 dias.

Vista por nosotros el $1 .^{a}$ de diciembre de cse mismo año, comprobamos una esecliosis dorsal izquierda de 5 cms., con gran desequilibrio y curvaduras invereas de compensación supetior e inferiot, como puede verse en la fotografía. Además, tigidez muy rarcada de la columia con corrección nula a la suspensión o flexion del tronto adelante. El estado general era deficiente; babía desnatrición rarcada, hipotonia muszular, palidez. Iniciamos una cura kinésica en el servicio de Kinesitetapia del Hospital Arriarán, con intermitencias rortas de dias o semanas. iurz que se prolongó por espacio de 2 años. Dutante el primer tiempo nos ayudamos con un jecho de yeso, corrextivo. para la nocbe. Despaés de obtenida alguna. flexibilidiad raquidea con la gimnasia. colacamos un corset de yeso, correctivo, que mantuvimas por tres semanas $y$ después de un nuevo petiodo de 2 meses de gimnasia un gundo. corset. que mantuvimos otras 3 semanas. En el signado zin hemos zompletado el tratamiente gímuástico con un corset correctivo amovible. en cuero y matal. 
Durante la cura kinésica bemos notado una apreciable mejoría del estado seneral. anmento del paniculo adiposo $y$ evidente acentuación de iz musca* ¿asción. La rigidez raquidea ba desaparecido, obteniéndose ula flexibilidad mayor que la que observamos corrientemente en níñas de la misma edad. Ĺa escoliosis se ba corregido casi totalmente, desapareciendo el desequilibrio, como pirde apteciarse en la fotografia. En resumen, se ba obtenido un resultado altamente satisfactorio- para quien conozca las enormes dificnltades que oponen las escoliosis para ser modificadas.

CASO 2. - G. P., 8 จños. Majer.

Nacida normalmeate. A la edad de 3 años y meses adquirió por contagio dirzeto una taberculosis pleuro-pulmonar izquierda, que evoluciona lentamente bacia la curación por espacio de algunos años, con gran tendenciz a la fibrosis plearal.

Despaés de algunos meses de iniciada la afección, aparece una retracción ticatricial plearal progresiva por espasio da varios años, que trae como con*ecuencia una gan asimetria torácica son la escoliosis de grandes propoxciones que muestra la fotografía.

En este estado la vemos en enero de 1940 y comprobamos lo gas sigue: Gran escoliosis dorsal derecha de 8 cms. con un desequilibrio de $81 / 2$ cnss. tes decir, que la apofisis espinosa de la 7,3 cervical queda a $81 / 2 \mathrm{cms}$. a la derecha de la vertica!, que pasa por la extremidad superior del pliegue intergiúteol. Curvadura dorsolumbar izquierda de compensación. Guan igibosidat costal con alejamiento de $10 \mathrm{cms}$, del borde interno del omóplato izquierdo. Gran disminución de volumen del hemitórax afectado (izquierdo) en todos sentidos, habiéndose reducido su perimetro a sólo 25 ems. tomado por debajo del ángulo inferior del omóplato. Capacidad vital al espirometro, de solo $300 \mathrm{cms} \&$. Rigidez muy marcada de la columna. No se aprecia corrección algana a la suspensión.

Se intenta corregir en el Servicio de Cirugía y Ortopedia del Hospital Arriarán, con corsets de yeso alternados con series de gimnasia ortopédica y respiratoria. Se coloca un corset el 5 de febtero, otro el 28 de marzo y un último corset el 26 de junio. sin obtener g gran cosa, perdiéndose despues de vista 13 exfermita.

Mostramos este caso por tratatse del úrico caso de escoliosis por tuberculosis plenropulmonar de entte los observados por nosotros y por presentar. en su grado máximo, la sintomatología típica de $l_{2}$ escoliosis pleoritica. Nos muestra hasta quê panto puede alcanzar la intensidad dế proceso cícatricial y hasta que extremos poede Ilegar la deformación cuando no ge le opone algún tratamiento preventivo. 
CAsO 3. - C. A.. 6. años. Mujer.

$\mathrm{H}_{2}$ sido san's. En setiembere de 1939. brascamente, egtado infeccioso con fibbre alta. A los 10 dias, punción de la cavidad pleoral derecha da salida a nn litro de pus. Se trata por espacio de un mes y medio con digenán por via oral y endopleural. Durante este tiempo se practican periódicamente 22 puntiones pleurales evacuadoras, Heggándose por fin a una pleurotomia mínima $y$

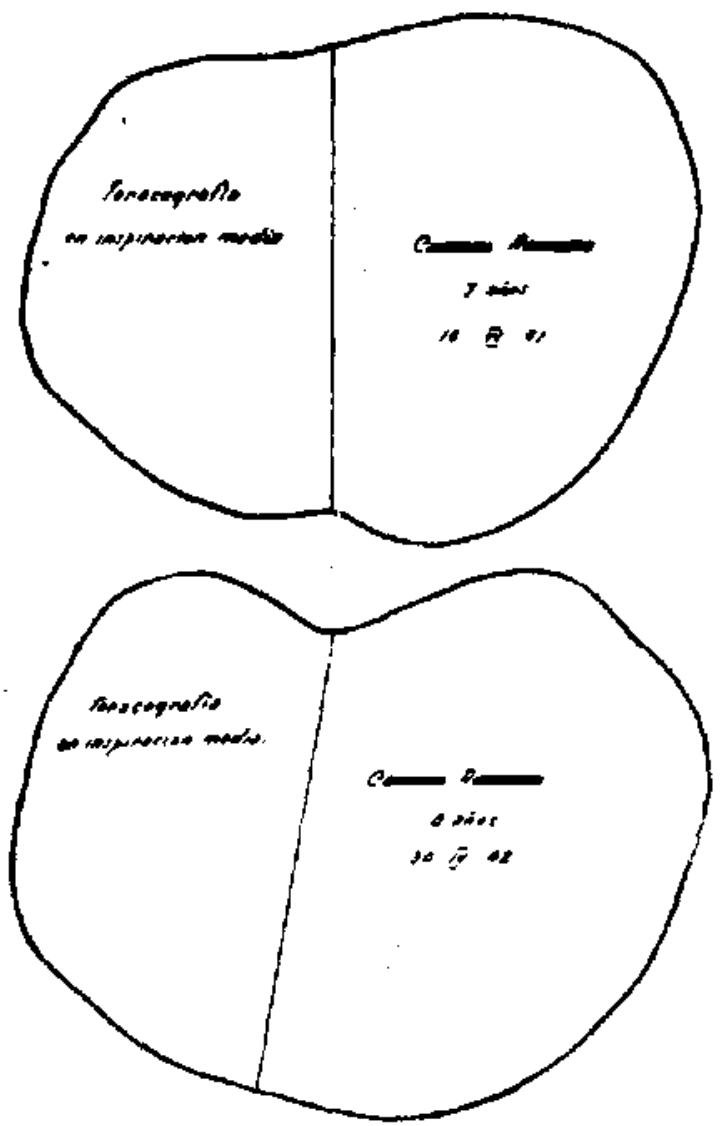

CASO N.3.-Toracografía.

tun mes después d: ésta, a una resección costal. La supurạción continuó basta los primeros dits de abril. En resumen, el proceso supurativo pleural dacó 7 meses. Vista por nosotros en junio de 1940. comprobamos escoliosis dorsal izquirda total de 7 cms. con un desequilibrio de $3 \mathrm{cms}$. es decir, que ta apófisis epinosa de la 7.* vertical quedaba a 3 cms. a la izquierda de la vertical que pasa por la extremidad superior del pliegue interglúteo: elevación en 8 cms. del ángulo inferior del omóplato izquierdo; fuerte retractión del be- 
mitórax derecho $y$ rigidez raquidea tan mareada, que el tronco sólo podía desplazarse en bloque. Circunferencia del hemitótax derecho de 30 cms. y del hemitórax izquierdo, 25.5. Altura. $1.13 \mathrm{mt}$.

Siguió un tratamiento gimnístico ortopédico de 60 sesiones, con numerosas intermitencias, en la Sección de Kinesiterapia del Instituto de Educación Física. En setiembre de $1940 \mathrm{se}$ ayuda con an. corbet corretivo en yeso, que m.ntienc 45 dias. En seguida usa un corset amovible en coerpo y metal. En octnbre de 1941, auevo corser de yeso indicado por el próesor Díaz Lira, que es manterida por espacio de 5 meses. (Nosotros no somos pattidarios de mantenet en estos casos un corset de yeso tanto tismpo. Preferimos japsos que varian de 20 días a 2 meses. para movilizar la colamna y ejercitar la mus. culatara entre uno $y$ otro enyesado).

Durante el tratamiento gimnástico se observó uni norable y plogresiva disminución de la rigídez tóracoraquided. un mayor dominio y desatrollo de la nusculatura y una mejoría creciente del estado general, corroborada por un constante y aceletado aumento de peso.

La corrección de la desviación raquidea se obtuvo también en form. apreciable, pero la disminución de volumen del bemitórax izquierdo apenas se modificó. Examinada el 28 de marzo de 1942 , la escoliosis era de $31 / \underline{1}$ a 4 crus. en vez de 7 y el desequilibrio de 2 cms en vez de 3 ; ei, perimetro extersa del hegritócis derecho, dx 34 cms. en vez de 30 y el del hemitórax izcuietco, de 26.5 en vez de 25.5; la altura, de $1.24 \mathrm{mt}$ y el peso de 30 kgis.

CASO 4. - Y. M., 20 añios. Hombre.

Dice haber presentado a la ladad de 8 añlos and plecritis dercecha con deraame, que fué operada. vaciándose un líquido claro $y$. al cabo de algún tiempo, membranas de quiste hidatídico, cicsttizando ia herida después de algunos meses. Cierto tiempo después, que no sabs precisar, sa estableció una desviación raquídea.

Lo vemos en marzo de 1934. época en que presentaba una escoliosis dorsal izquierda de 3 cms. compensada con una curvadura lumbar derecha de 3 cms., como pucde comprobarse' in la forografia. pues el hilo a plomo coinside a la vez con la apófisis espinosa de la 7 , carvical y la extremidad superior de' pliegue interghiteo. Existia hundimiento a nivel del himitórax darecho, omóplato izquierdo 3 cms. más alto que el detecbo y la escoliosis era parcialneate modificable con la flexión dal tronco. Capacidad vital. 2,400 c.c. Llams la atención en la fotografia el buen desarrollo muscular, lo que bace sospechar desde el primet momento que se trata de una ssciliosis por causa extravertebral.

Este eafermo pudo seguir una cura kinésica mas o menos intensa, aunque di sólo an mes de dusción. lo que. sin embargo, prodajo una disminnción perceptibie de ambas curviduras $y$ an aumento de la capacidad vital 200 cé. 
CASO 5. - E. L., 7 años. Hombre.

Ingresa al servicio de Cirugia del Hospital Arriarán el ij de eneto de 1940. con estado general deficiente y con una fistula plensal izquierda, suparando con regular intensidad. Presenta nia fuerte ratracción dal hemitórax izquierdo con escoliosis dorsal derecha desequilibrada $y$ bastante rigida; más una cscoliosis lumbar izquierda incipiente, de compensación. Piel pálid.. faz algo valtuosa, animo decaido. camina timidamente, llevando el tronco en actitud de defensa contra la movilización de su hemitórax izquierdo, semejante a la presentada por la fotografia del caso 8 . La sedimentación era de 37 y $64 \mathrm{mms}$. en la 1,7 y la $24^{7}$ hora repectivamenz. Lx radiografia mostraba imagen de hid̛́ropneumotórax izquierdo y sombxa de pạnaipleuritis.

Habia sido operado de un empiema pleutat, seguramente pnenmocócico. como sz verá más adelante. Tres meses atrás, plaurotomía minima, debiendu reoperarse despoés, esta vèz con resección costal, en fecha que no es precisa. A1 cabo de 20 días de curaciores ${ }^{\circ} y$ drenajes de caucho. como signiera en las mismas condiciones, se nos to entrega para ensayat una cuta de gitmnasia respiratoria $y$ ortopédica progresiva $e$ individual, la que se inicia con sesionts diarias en la sala de gimnasia del Hospital, observándose un mejoramiento realmente ineșerado en cuanso a su rapidez se refiere. Al cabo de un mes, iu sstade general habia ganado francamente. subiendo el piso, anmentando el apetito: acrecentándose la espacidad vital. desapareciendo la astenia y mejorando la función neuromuscilar de tal manera que era capaz de marcbar tesueftamentz, forrer y realizar de memoria y eatusiastamente ano tras ot to los spercicios gimnásticos de Ia lección. Lu excoliasis y asimetría tarákica se modificaron muy notablements, anque sin desaparecet. tomando el niño el aspecto que muestra la fotogeafia. Desgraciadamente no str hibia tomado fotografia antisior $y$ tenemos que atenernos sólo a los datos clínicos. En cuinto ? la fistuia se mantenía siempre; pero con sufuración decreciente.

E1 30 di mayo de 1940, sin conocimiento nutstro, fué sometido a una totzcoplastía con resacción de la $7,3,89^{2} 9.7$ y 10 . costilla 16 a 8 cms.), falleciendo e] niño al dia subsiguiente.

CASO 6. - J. B., 20 años. Hombre.

Salvo cscarlatina, coqualuche y sarampión en la infancia, tha sido sano. Ha practicado atletismo con entusiasmo, carteras de velocidad especialmente. en los áltimos aíos.

Prosenta a los 19 años una discreta lesión pulmonar derecha, tuberiulosa, que se trata desde el comienzo con pneumotótax. complicándose a los 3 meses de un empiema pteural a estreptococos que fué traxado con punciones $y$ iavados intrapleorales de un preparado sulfahilamidado que no recnerda y sucro fisiológico. surando al cabo do o meses, pero presentándose al mismo tiempo unz deformación tocacortaquidea de carácter progresivo. Se trata de un muchacho longifinco astético, presentando un hurdimiento del hemitórax datecho muy evidente $y$ marcado en su parte anterior, y ana escoliosis doral 
izquierda de 4 cons., desequilibrada, con desequilibatio de $1 \frac{1}{2} \mathrm{~cm}$. y elevación ea 5 csos. del omóplato izquierdo. Leve corrección a la flexión del tronco adelante. La circanfarencia del bemitórax derecho es de 35 ctms. en ba inspiración media y no se modifica con $\mathrm{la}_{\mathrm{a}}$ inspiración máxima. El hemitórax ixganierdo mide $40 \mathrm{cms}$. en inspiración media y llega a $43 \mathrm{cms}$. en itrspiración míxima. Rigidez raquidea muy marcada. Feso, $50.600 \mathrm{kgrs}$.

Desda el 15 de abril de 1941, cura kimisica con sesiontes diarias de gimnisia ortopédica y reeducación respiratoria, que contimía con sólo ligetas interrupeiones hasta enero de 1942 .

Examinado en marzo de 1942 puede notirse un mareado progrzso en carrto a la flexibilidad raquidea, soltara en general y movilidad costal. Ha aparecido, por ejemplo, elevación de las costillas inferiores en el hemitórax derecho dunante la inspiración, lo que al comienzo no era posible. La scoliosis misma sa corkegido an $] \mathrm{sm}$. Peto en cuanto a ampliación del hemitórax retrádo, el resultado ha sido nulo. En cambio, el lado sano ba anmentado su perimetro en $1 \mathrm{~cm}$.. produciéndose una hipertrofia palmonar compensadora de ese lado, con to que el desequilibrio voluméttico entre los dos hemitórax se ba hecho mayor.

CASO 7. - F. 1.. 14 años. Hombre.

Anticedentes de tuberculosiz pulmonar en la familia. A los 3 años de edad, neumoníz seguida de una plentitis izquierda con empiema, que fué operada con resección costal. después de algunas punciores evjtuadoras, cicatrizando y curando en poco más à mes. Despisés di ance años, $s$ queja de dblores en la región operata. Al examzn, en en:ro de 1941, eneuentra una neoliosiz dorsal derecha de 3 lí cms., desequilibrada, con ana curvadara lumbar izquierda incipiente, de compensacion. Hay un derequilibrio de $2 \frac{1}{2}$ cms. $y$ una elevación de 2 cms. del omóplato derecho. El hemitórax izquierdo es de menor valor que el derecho. Mide 32 cms. de circunferencia por 38 del derecho, en inspiración media Hay ligeta protuberancia costal y rigidez muy miscada del raquis. Se trata dz un niño longilíneo, asténico, de tórax may largo con ingufo xifoideo estrecho e intsuficiencia muscular may notabie, especialmente dorso-abdominal.

A principio de 1941 inicia un tratamiento kinésico, consistente en gimnacia general $y$ ortopédica insistièrdose especialmente en ejercicios respiratorios. conjuntzmente con an tratamiento tónico reconstituyente genetal, incluFendo belioterapia.

Practicó sólo 62 lecciorzs bajo control inmediato $y$ otras tantas según ias indicaciones dadas; pero 21 resultado fú realmente inesperado. Examinado rn abril de 1942. $1_{2}$ escoliosis ba disminuido a $\frac{1 / 2}{\mathrm{~cm}} \mathrm{~cm}$ la diferencia entre ambos hemitórax ha disminato en $21 \%$ cms., o sea, era ahora de $39 \mathrm{cms}$. al lado derecho y de $351 / 2$ a! lado izquie:do apreciándose un juego costal sa* tisfactorio a este lado. Ha desaparecido la rigider cocaco-raquídea. E1 desarro 

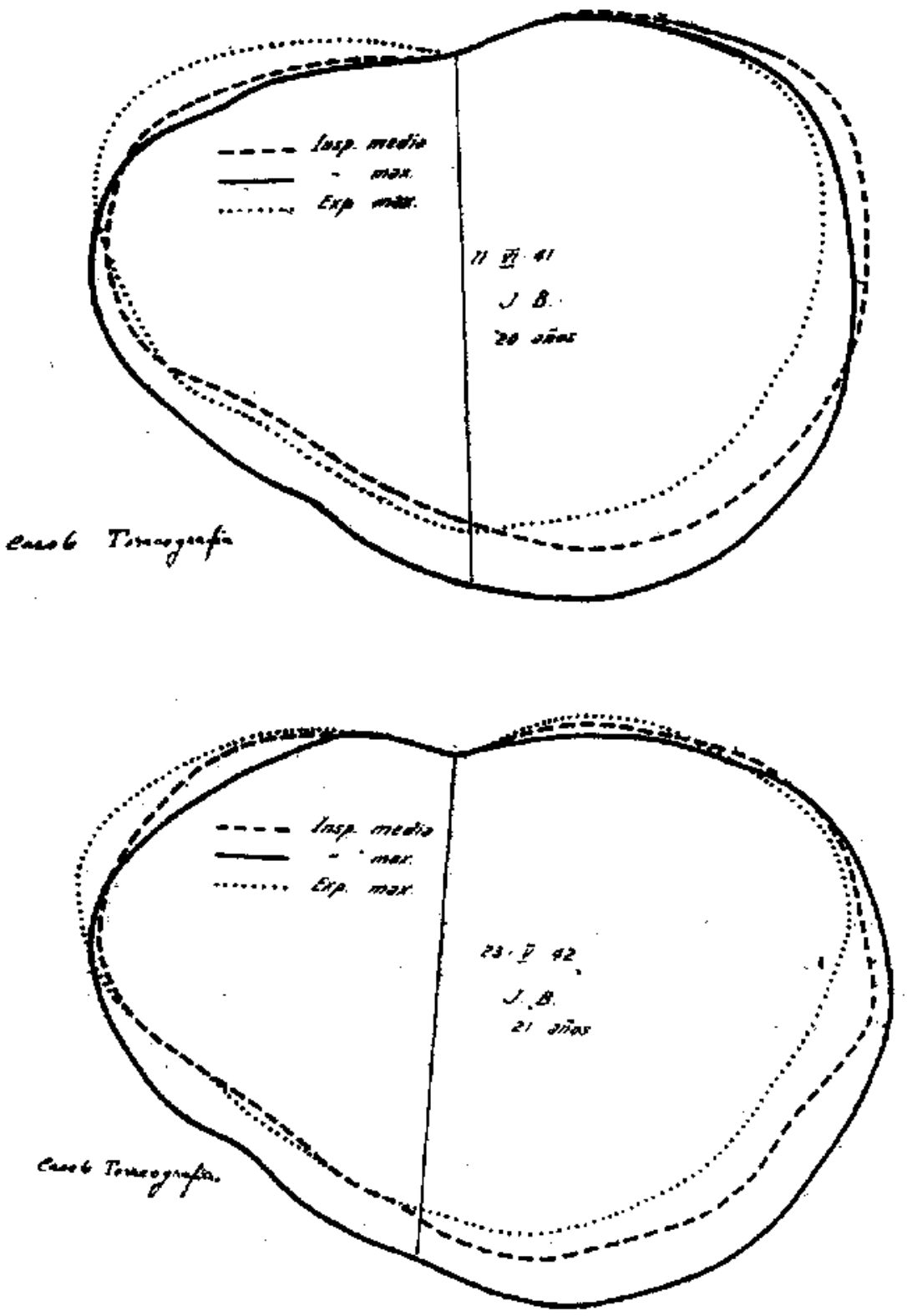

CASO N. 6.--Toracografía. 
Ho y el tonus muscular son mayoses. El astado general ba ganado en torma evidente.

CASO 8. - Y, F, 4 años. Mujer.

He sufrido de distrofia grave. Toxicosis, Bronquitis. Rinofaringitis. Bronconeumonia. Pleurotomia con resección costal el 11-I-1941, por empiema ixquirdo a pnetumococos tipo 1. con estado general geave, despues de 2 pun ciones prarticadas el 3 y el 8 de enzro con extracción de 1,000 y $400 \mathrm{cc}$. de pus respacivamente. Se estabiece una supuración crónica con alternativas de retención y vaciamiento. En abril de ese añto se nota una escoliosis dorsal dericha corregible à la susinensión.

Vista por nosotros el 28 de mayo de 1941, comprobamos nata escoliosis total dorso-rervical derecha de $2 \mathrm{cms}$, con elzación de $3 \mathrm{cms}$ del omóplato derecho. No se aprecia dessoujlibrio. Lo circunfetancia torácica media es fe 52 cms. El perimetro del hemitórax derecho es de 29 ims. y el del izquierdo, 23 cors. en inspiration media.

Presenta una matcada atilud viciosa (fotografia) con una defensa mus cular y rigider tal, que el tronco sólo puede movilizarse en bloque. Se inicia un tratamiento kinéstio, mientras la supuración contiótía. El 23 de julio de $194 \mathrm{j}$ se coloca an corset correctivo en yeso, an posición horizontal, corset que soporta mal. debrigndo abrise en valvas 20 dias después. Reinicia tratarínto gimnástico en diciembre de 1941. no aicanzando sino a practicar por espacio de 35 sesiones en tot?.

Dispues desapirece del Servicio y a pesat de reiteradas instancias por medio de la Visitadora Social. no se fogra que los padzes la envín al Hospital, por lo que la perdemos de rista.

CASO 9. - O. G., 10 años. Mujer.

No hay antecrdentes de contagio tnbereuloso. Ingresa al Hospitzl Arriarán en matzo de 1941 con un distrame ptrutal derecho $y$ un largo pasado bronequial, impreciso. Por panción se extraen 600 ce. de pus a pneumococos tipo 1. (Presenta ya una retracción del hemitótza derecho, a pesar de lia presencia del derrante, $y$ una escoliosis dorsal izquierda, rztracción y escoliosis que debemos suponet anterior a éste). E1 29 de marzo de 1941, pleurotomia con resección costal. Evolución may satistactoriz: et 9 de abtil de 1941 se $x$ :tira el tube de Delbet colocado darante la operación. dejándos drenaje de gasa que se retira el $16 \mathrm{de}$ abril. cicatrizanda ha herida rápidzmente.

E1 15 de mayo de 1941. esadro gripal. seguído de una gismétralonefritis aguda ane evoluciona faporablemente.

Vista por nosotros el 19 de agosto de 1941 . comprobamos una ejcoliosis dorsal izquierda de 4 ems. dezaquilibrada en $3,5 \mathrm{cms}$ y con una diferenciz de alrura de los omóplatos igual a 4 cms. El perímetro del benitórax deres cbo es $\mathrm{d} z 27$ cms. Y el del bzmitótax izqujerdo, dz 31 en inspiración medía.

Inicia una sarie de lectiones de gimnasia ortopédica el 20 de agosto de 1041. El 17 de setiembre de 1941 se coloca un enyesado correctivo, que se 


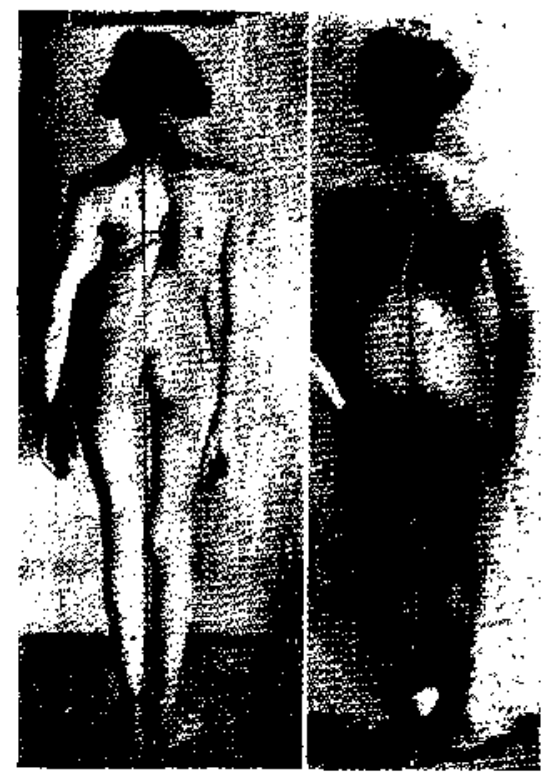

A.

B.

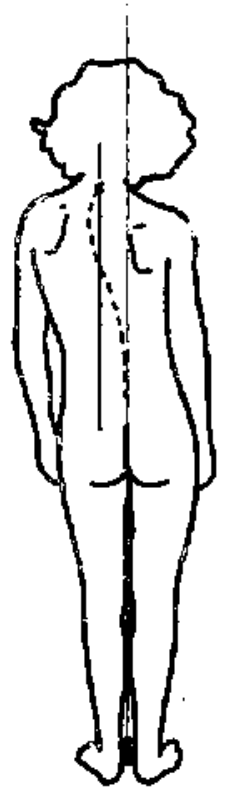

Fig. 4 .

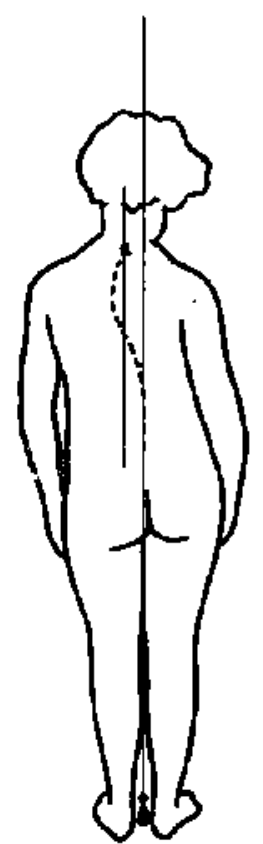

Fig. 5. 

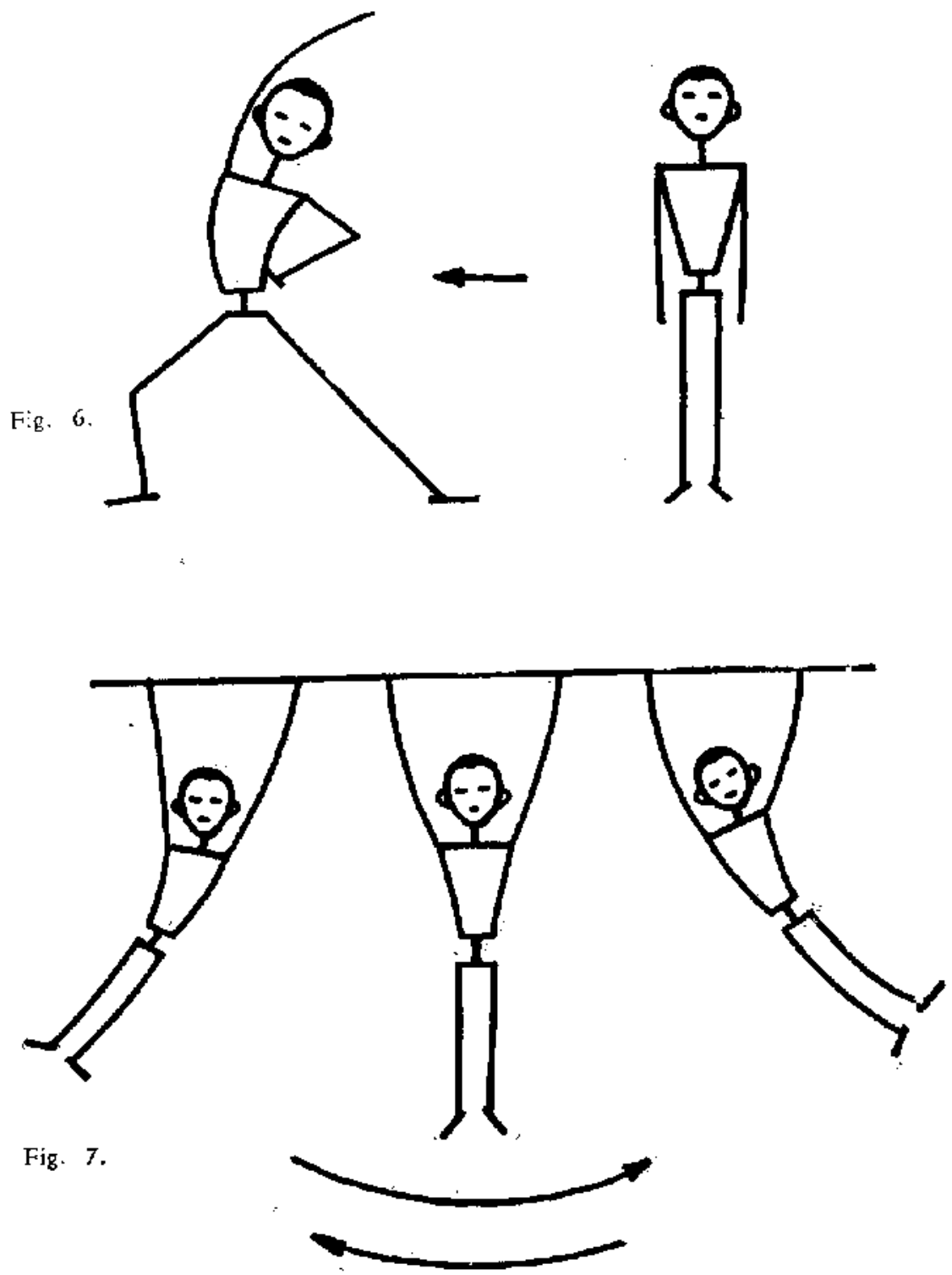

Algunos ejercicios cortectivos para escoliosis pheuriticas. 


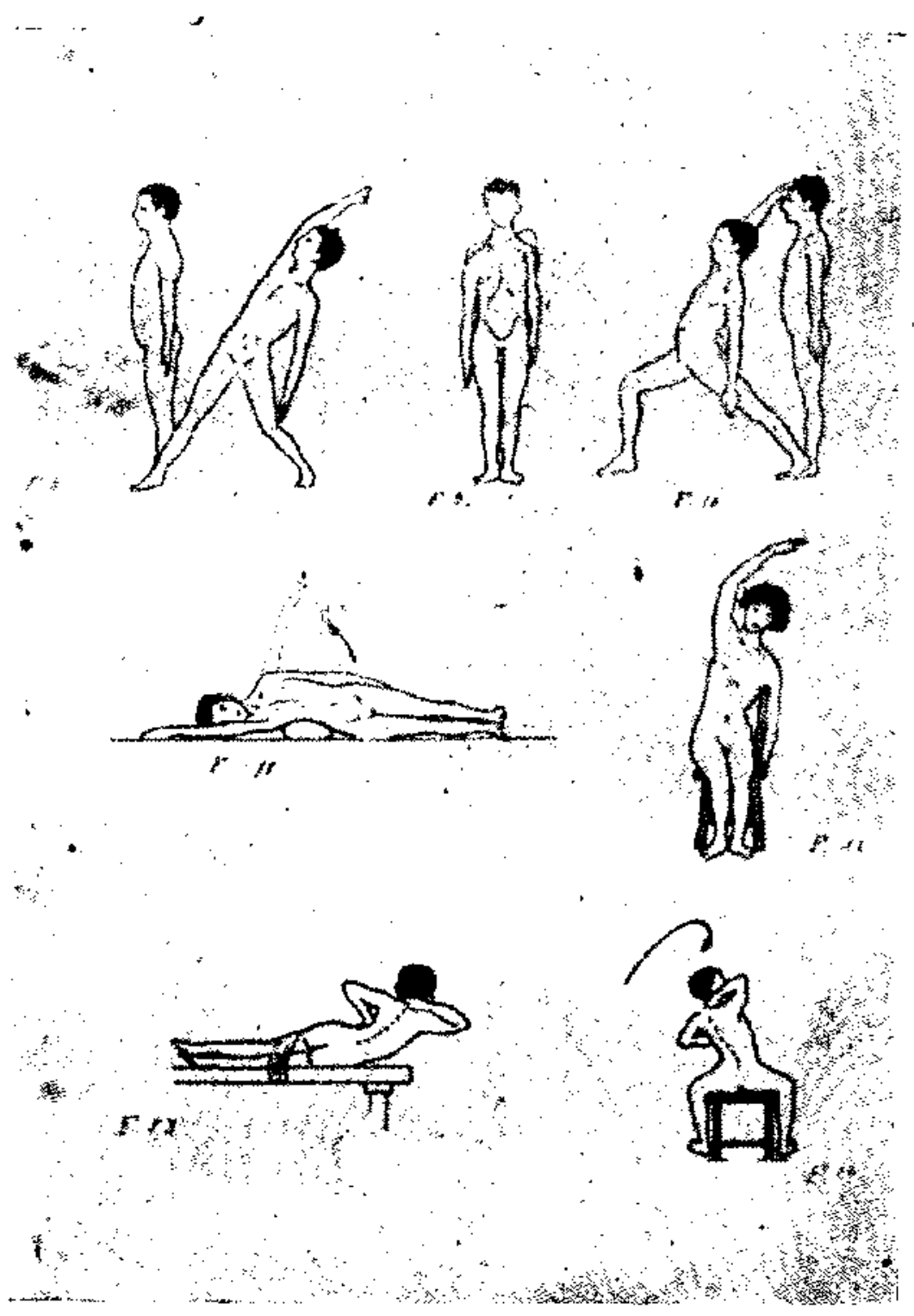

Figs. 8, 9. 10, 11, 12, 13 y 14.

Las figuras 8, 9, 10, 11 y 12 son tomadas da Georges Rosenthal ("Manuel Pratique de Kinésithérapie"). 

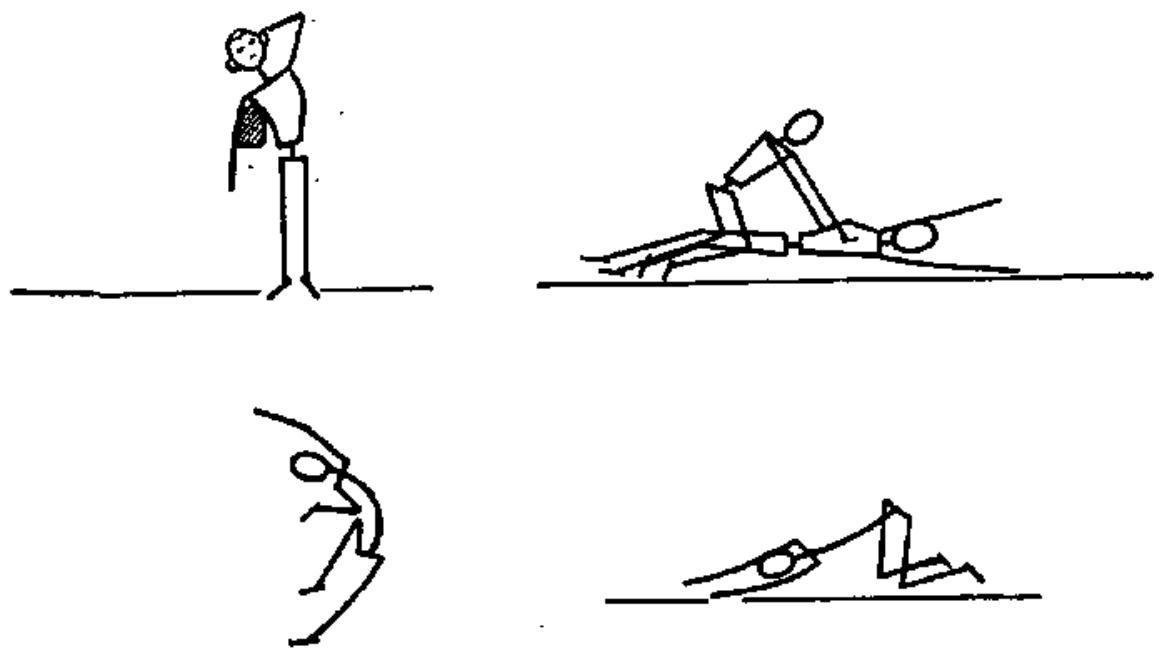

Figs. $15,16,17$ y 18.

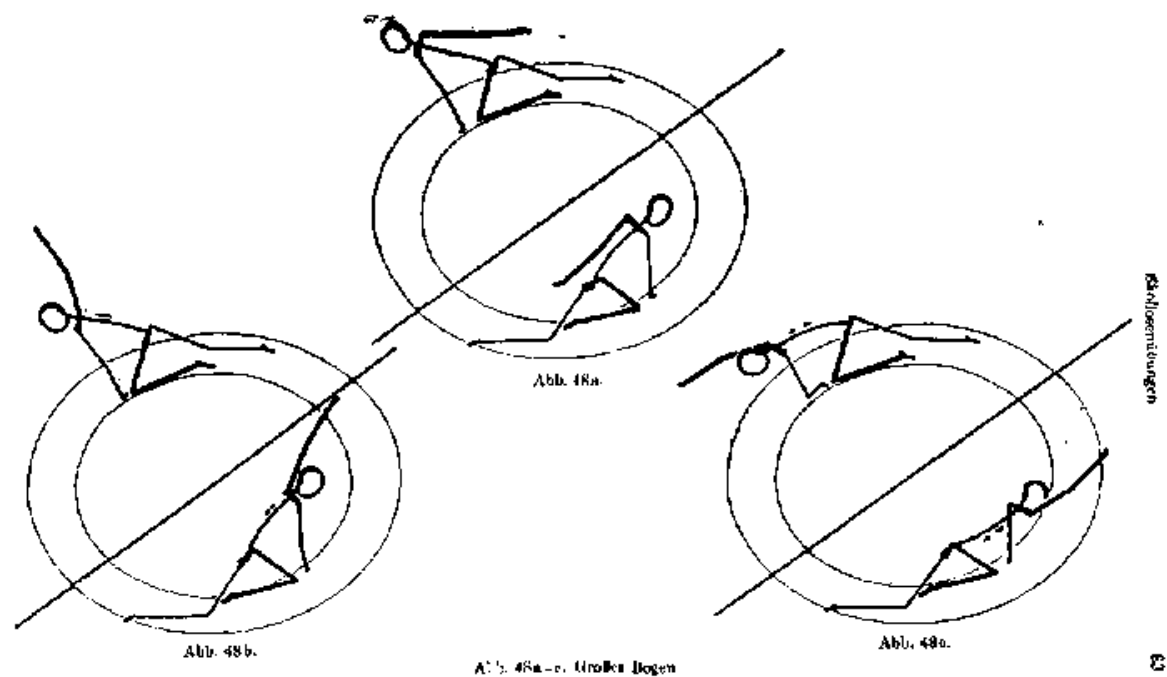

Fig. 19.

La figura $1 \vec{\jmath}$ representa un ejercicio respitatoti con apoyo latetal drl hemitórax sano sobre la barra sueca.

La figura 17 representa una acticud correcta en posición horizontal, boca abajo, sobte el piso. El bemitórax retraido es el derecho. 


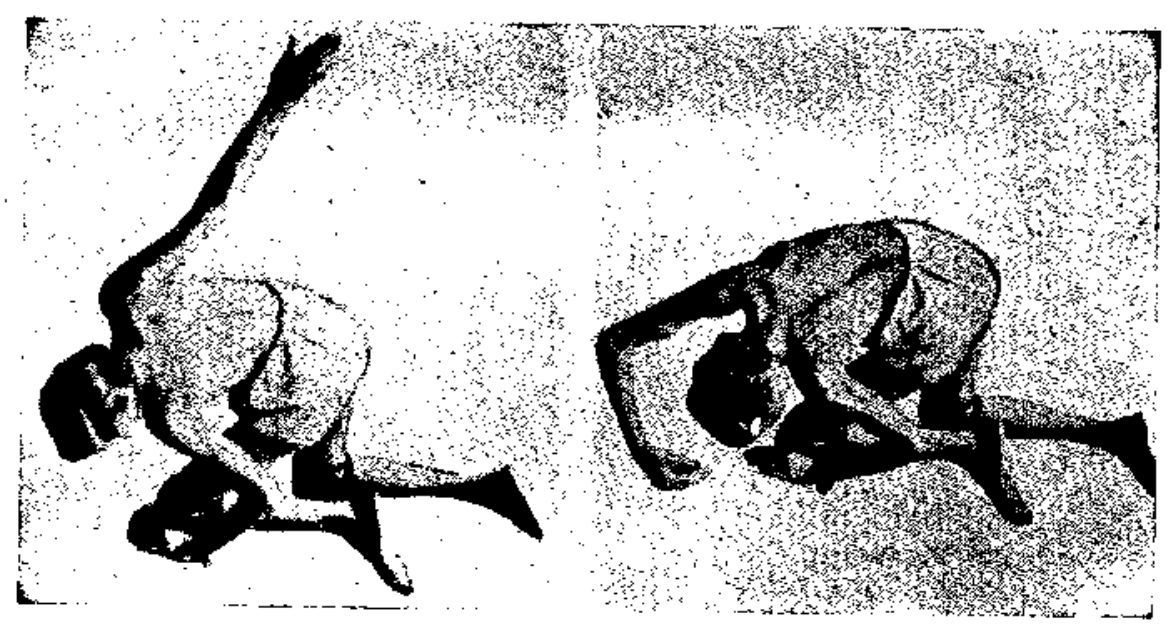

Fig. 20 .

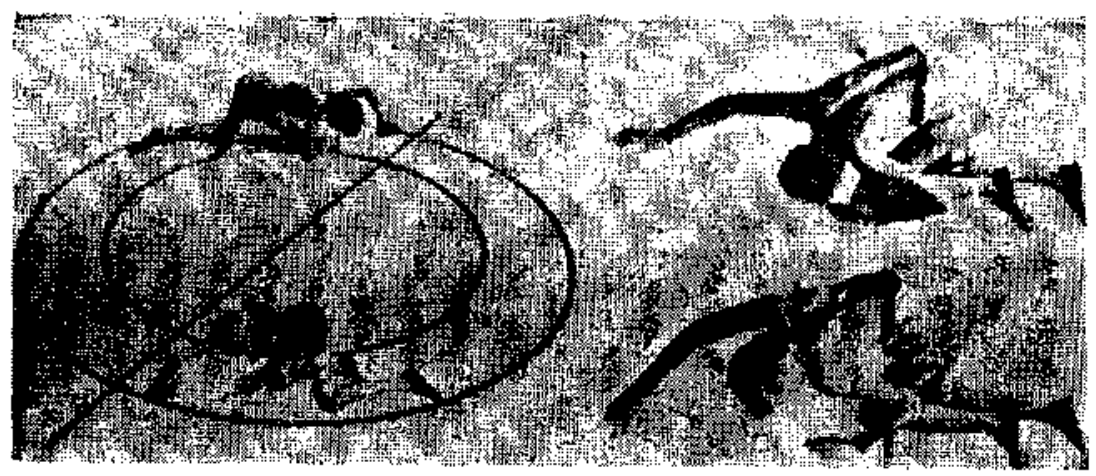

Fig. 21.

Las figuras 19, 20 y 21 son de Hohman \$tumpf ("Orthopadische Gymnastik"). Estas rreg últimas represiutan là marcha correctiva en suatro pies, de Klapp. 

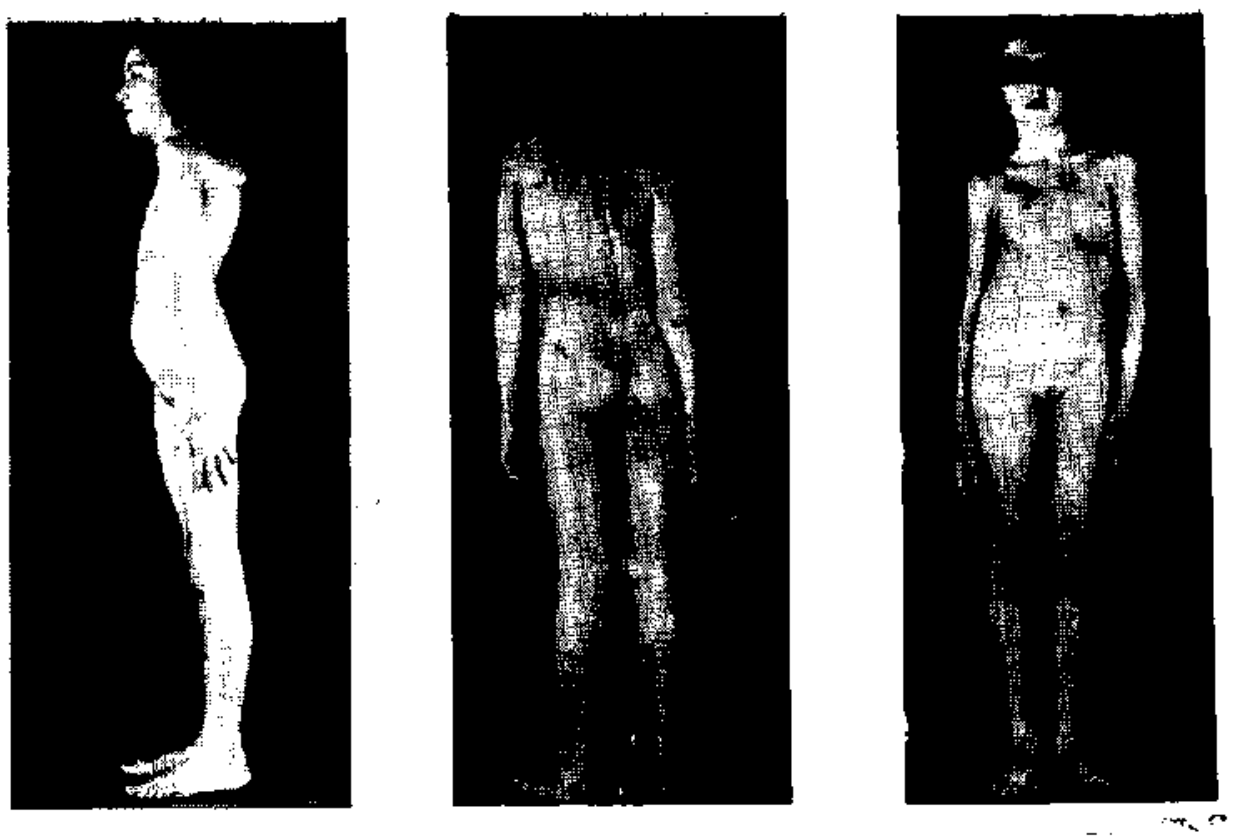

CASO N." 1.-C. C. 9a. Al iniciar la cura kinésica el 5-12-1938.
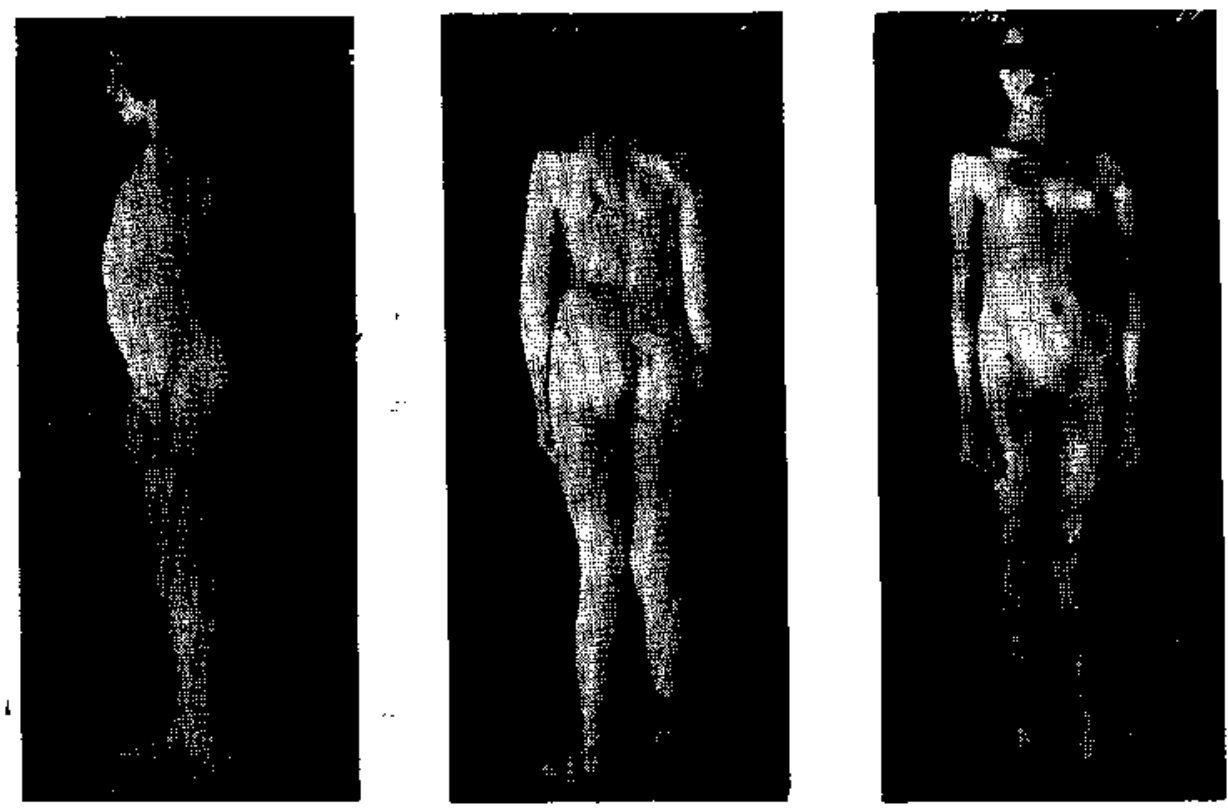

Caso N. 1 - C. C. Año y medio después de iniciada la cura kinésica. 


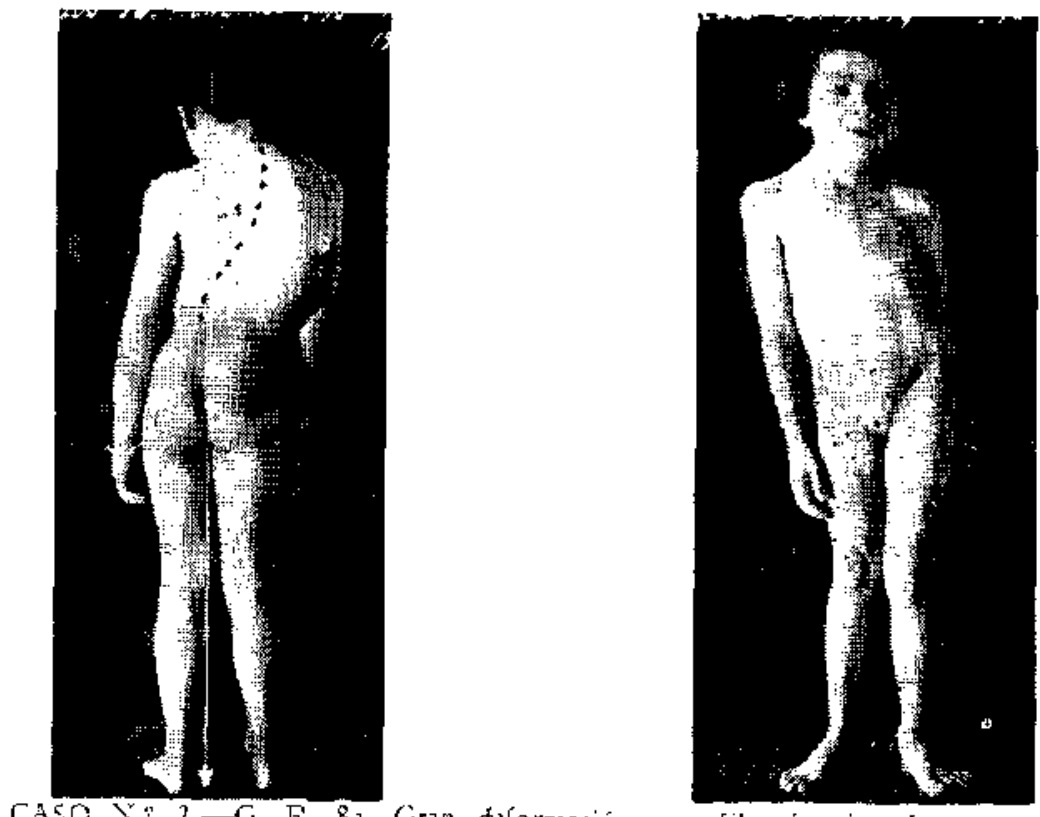

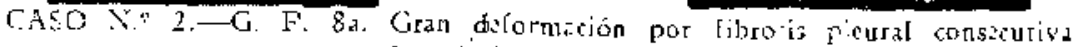
I tuizerculosis pleuropulmonar.

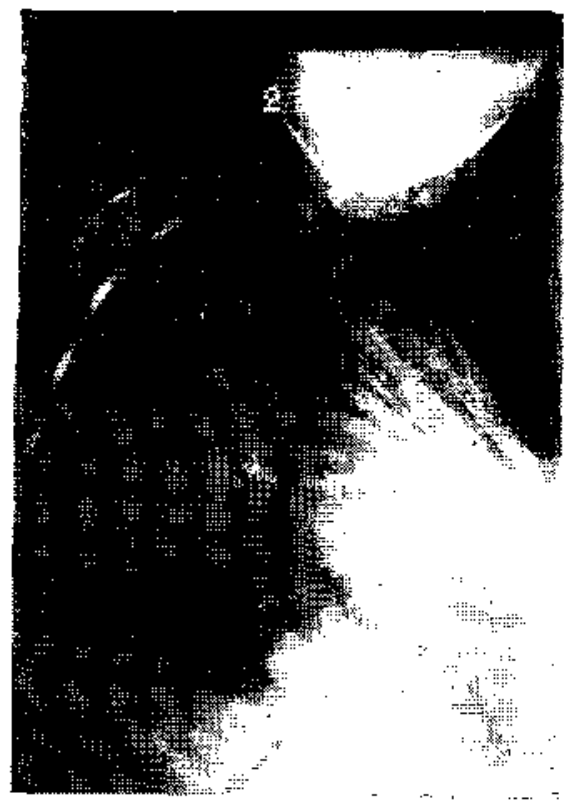

Radiegraf́a. Caso N. 2.

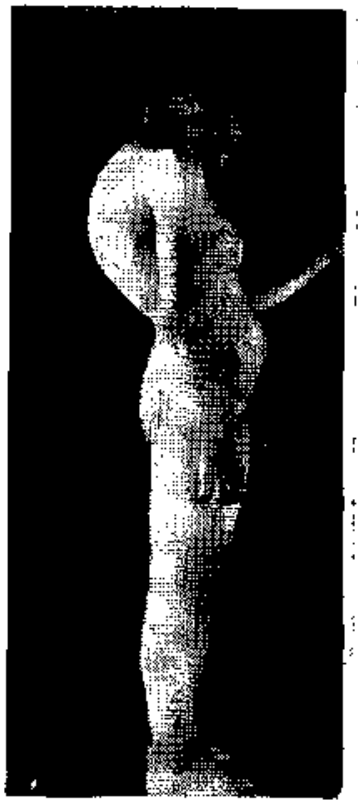

Caso N:= 2. 


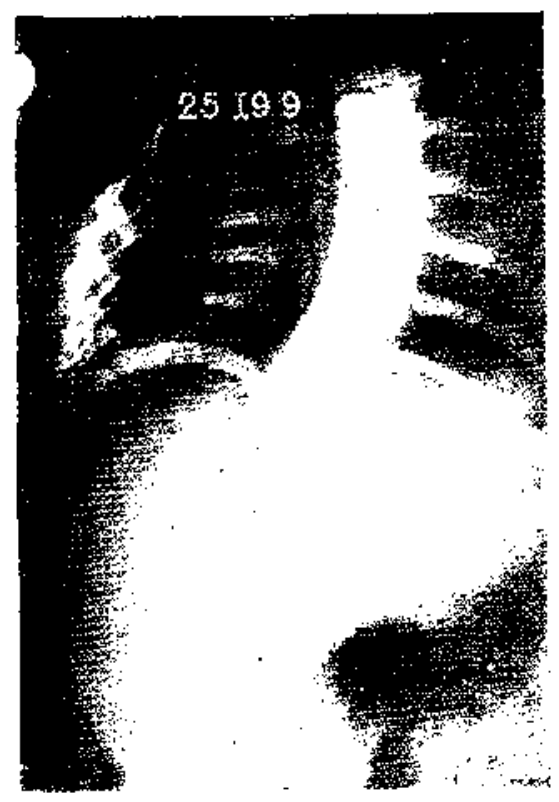

CASO N.: 3.

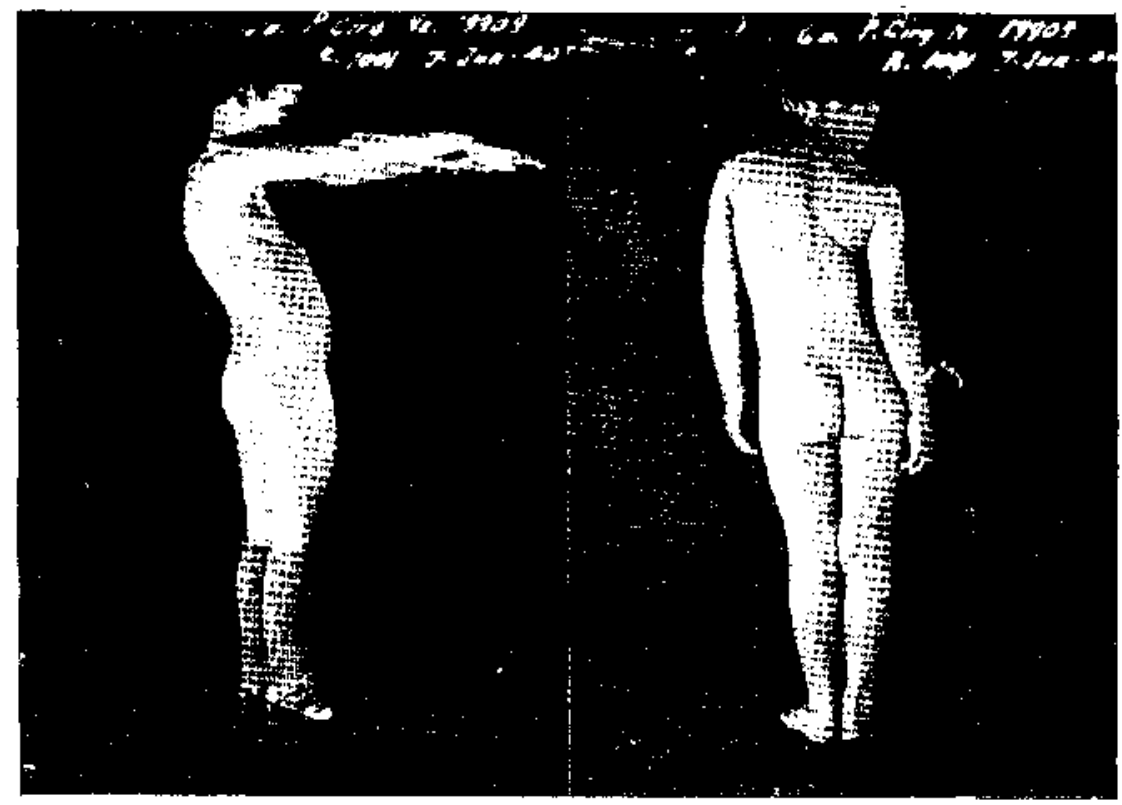

CASO N." 3.-C. A. Al inicial lin cura kinésica al 7.6-1940. 

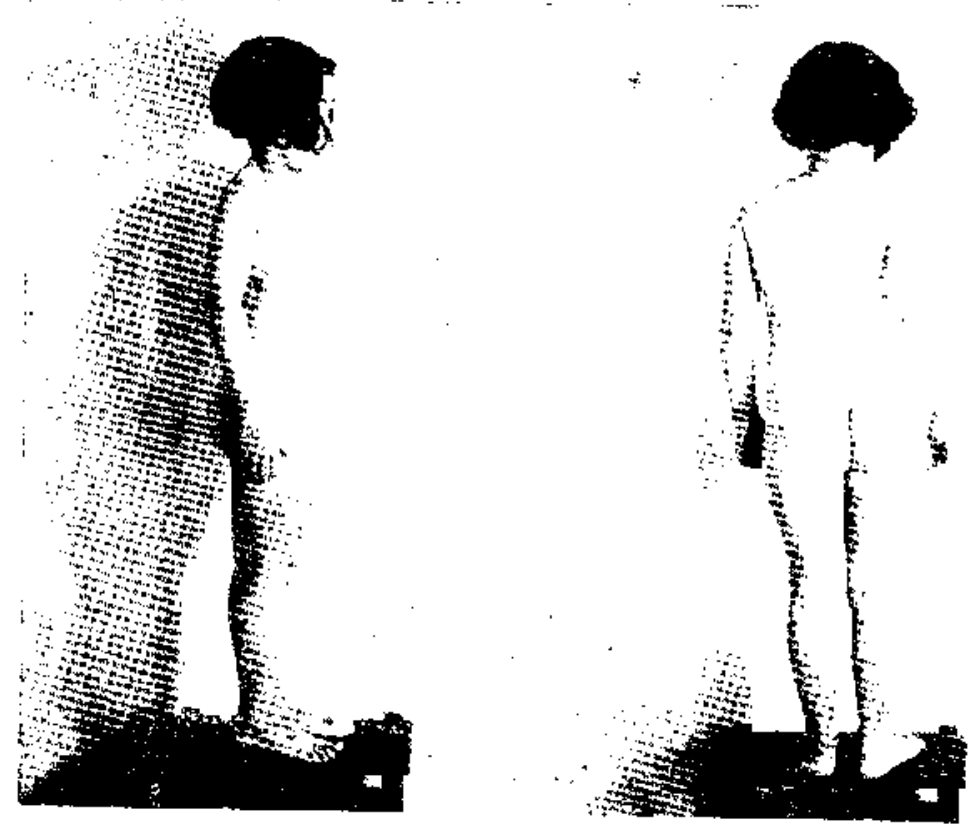

7

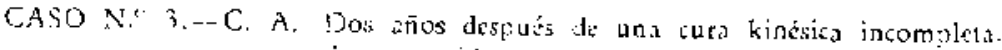
inturcumida varios veces.

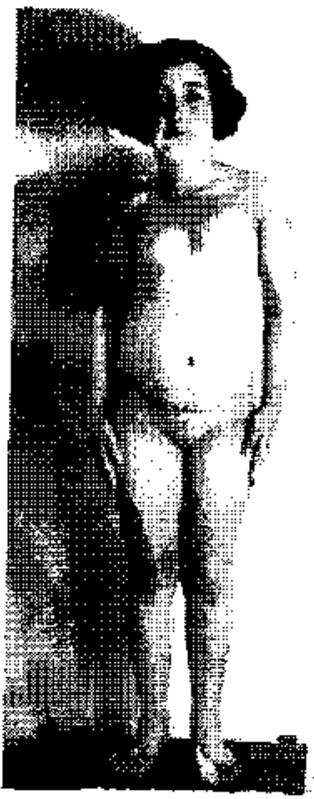

CASO N. 3

Dos aros dispué dal li cisti kineicis.

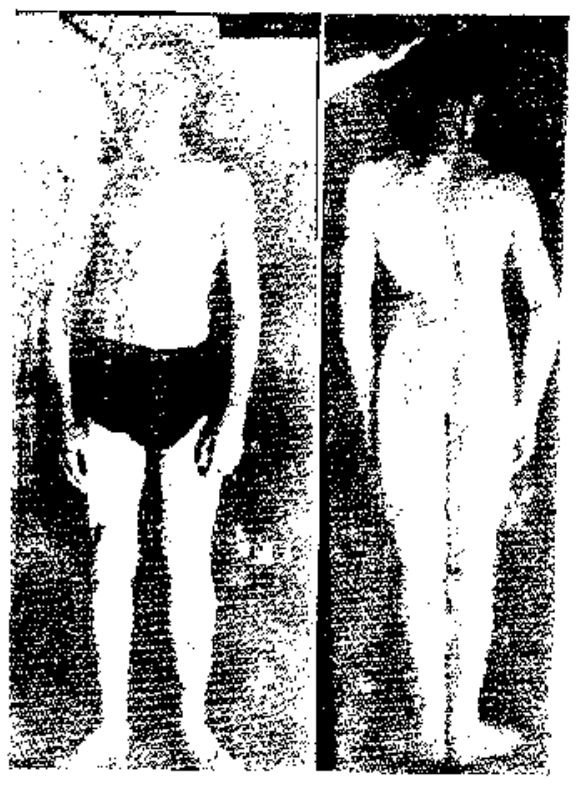

C.ASO N." 4.-.-.J. M. 20\%. Escoliosis pleuritic, constculisa a guiste hidasidico pleural. 

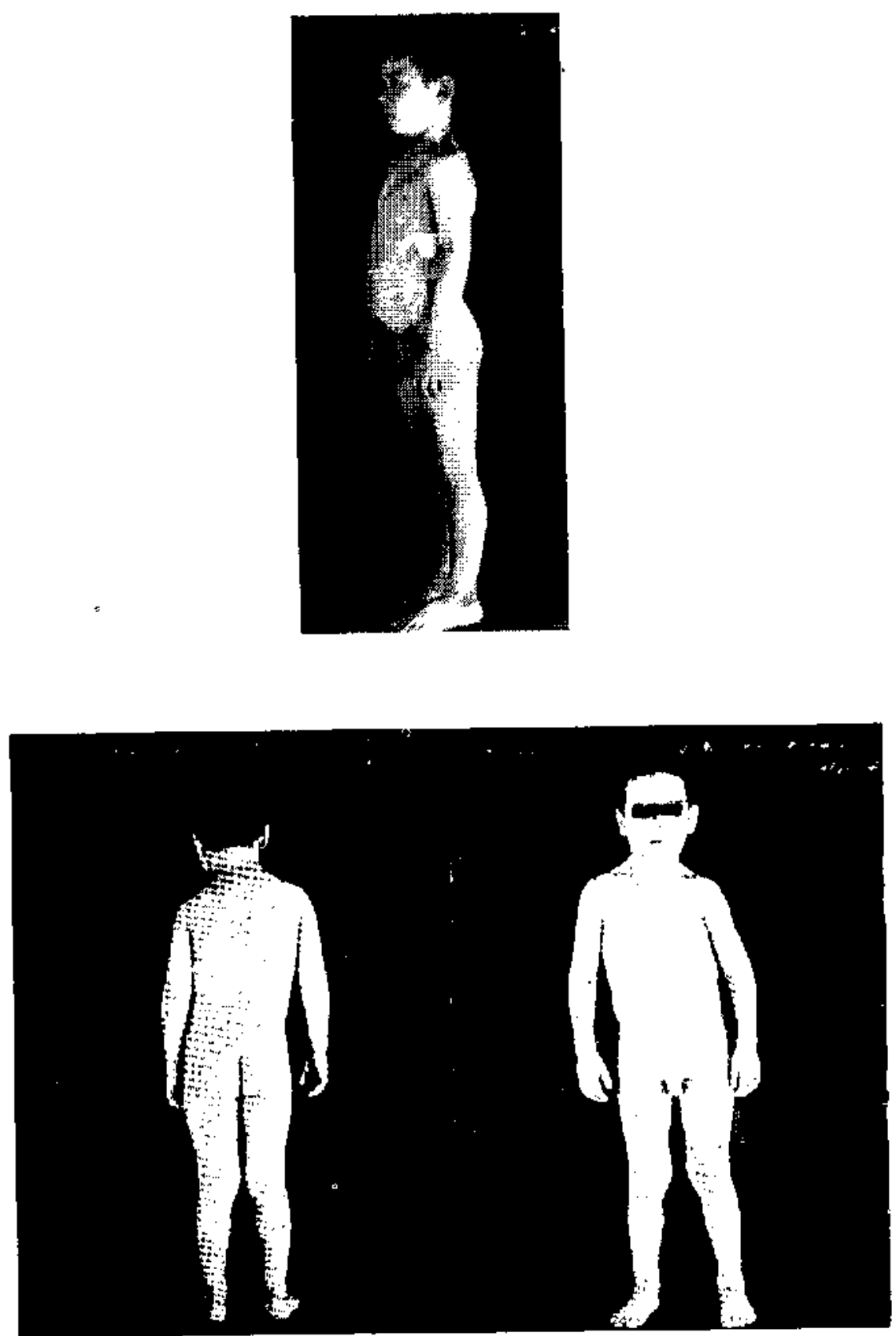

C.ASO No 5.-Después de un mes de tratamianto kinisico diario. 

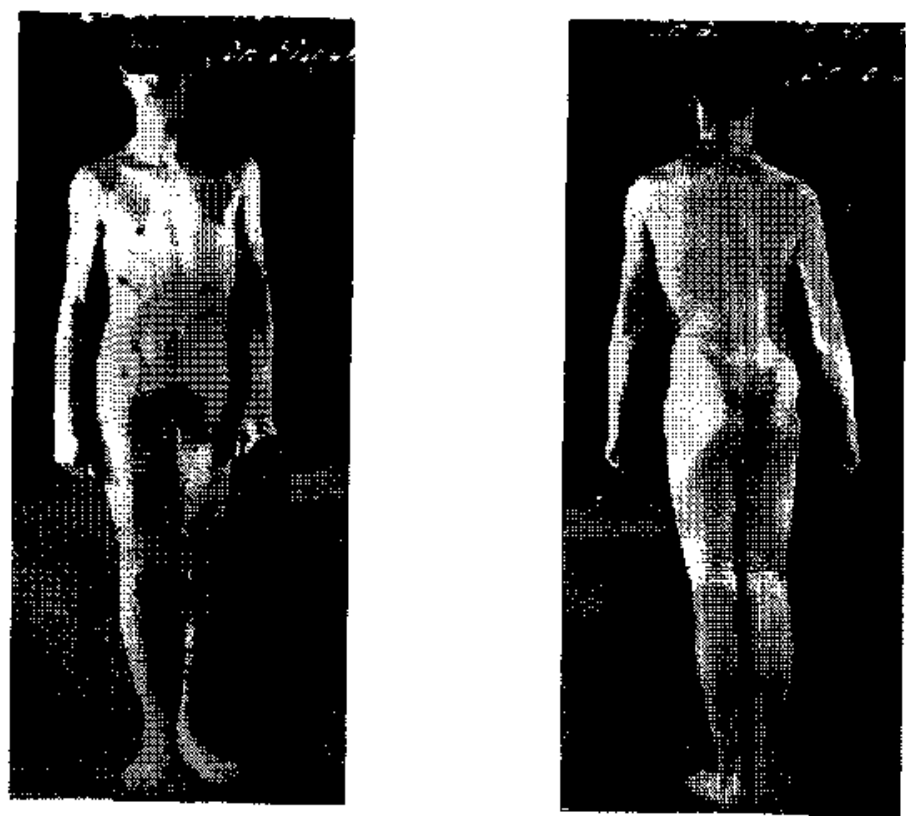

CASO N." 6.-J. B. 20a,

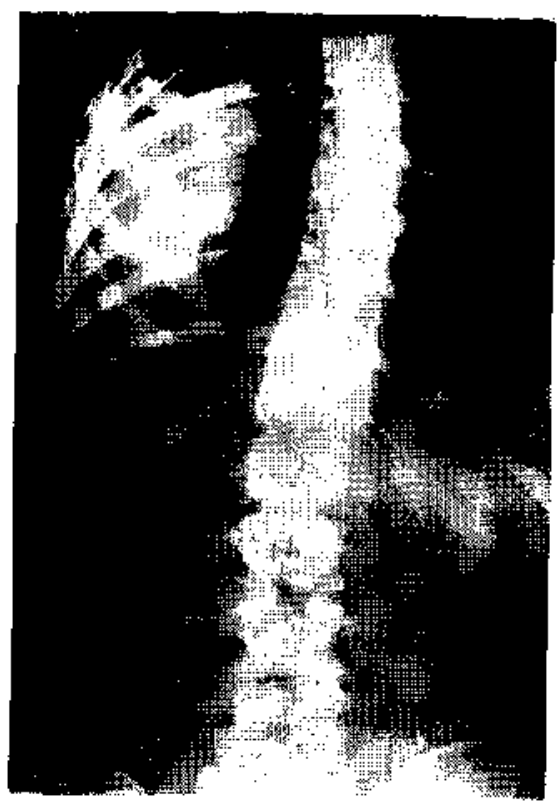

CASON N: 6. 

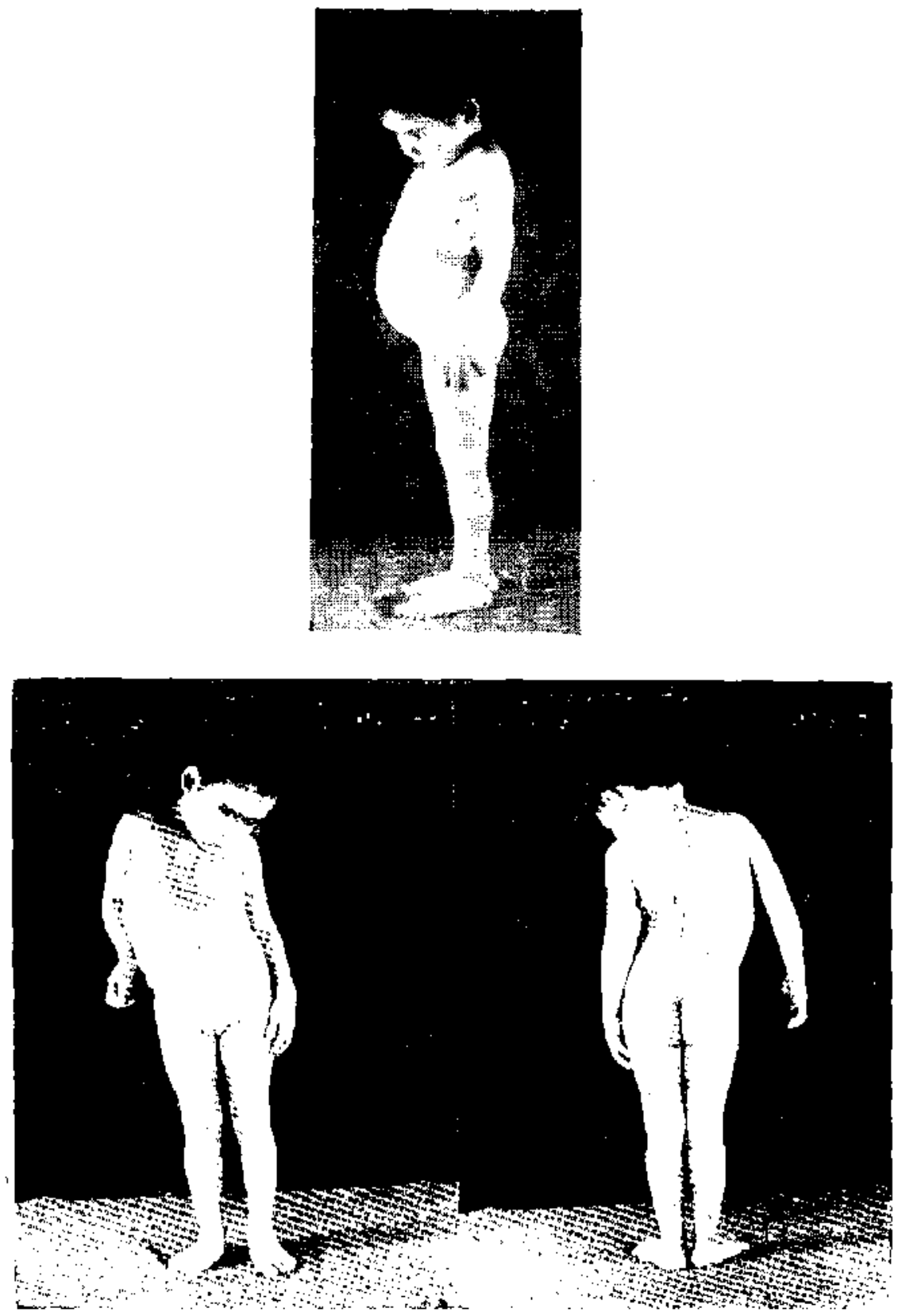

CASO N." 8,--Y', F. 4h. Al isiciut la cuth gimnática en mayo de 1941. 


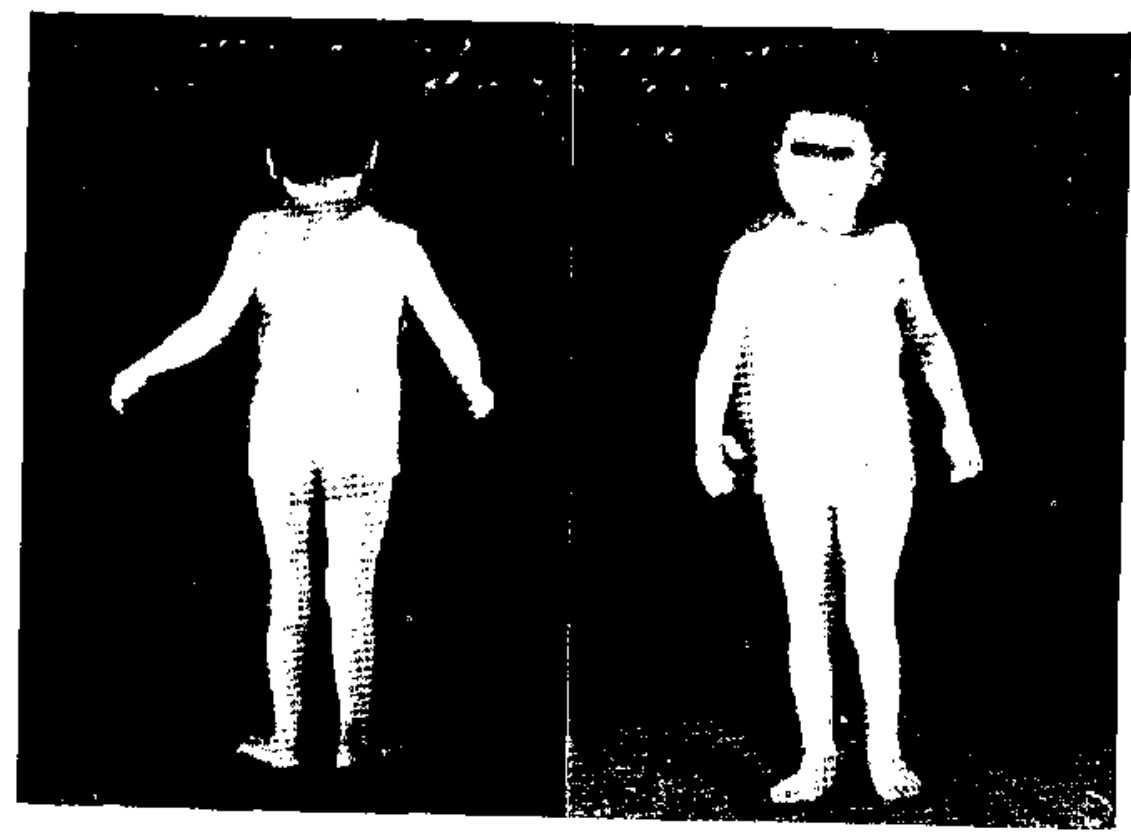

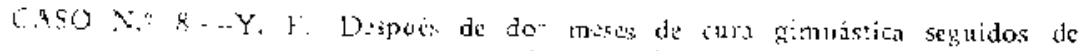
win enyes?da cortesiliso.

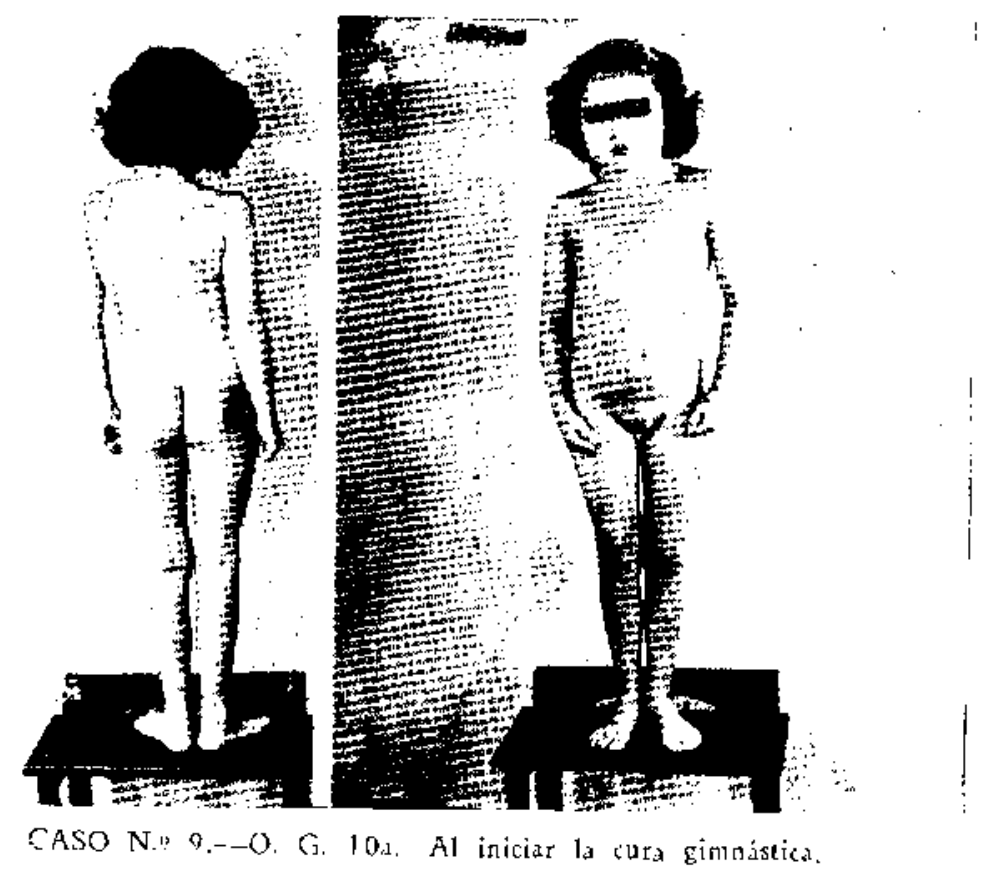




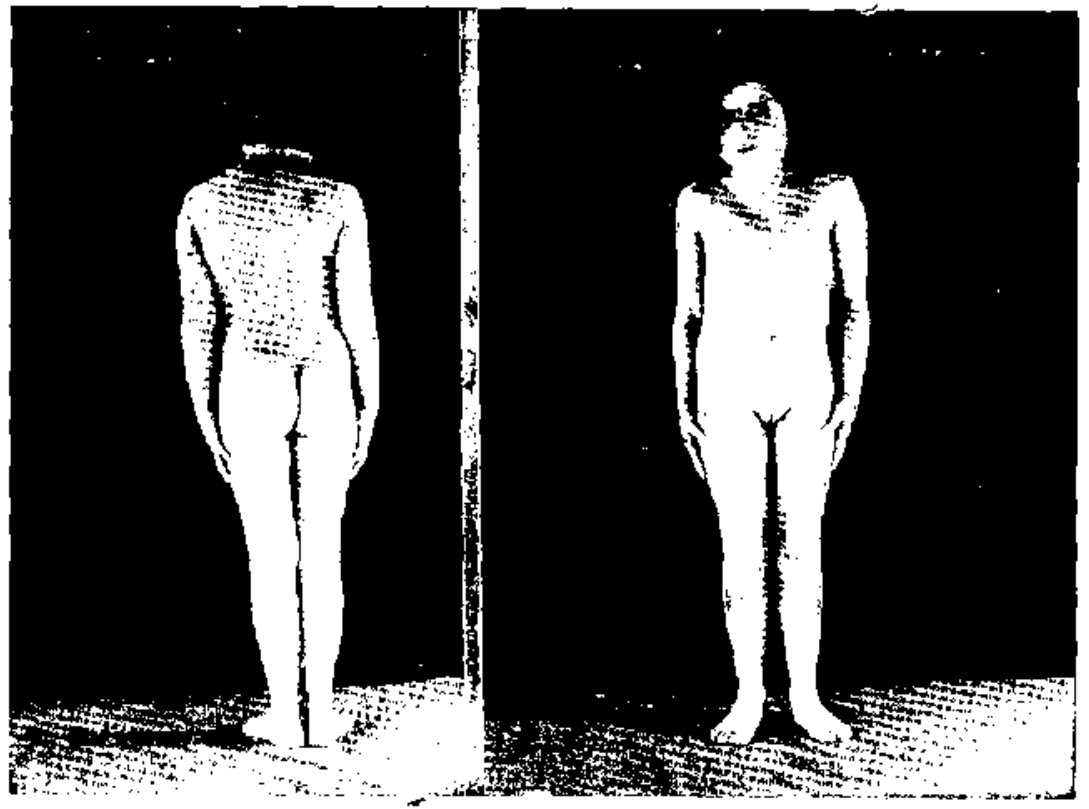

CASO N." 9.-O. G. Desvaés de una seria de 20 lecciones de gimasia y us enyesado correctivo (corset). mentenido durante un mes.

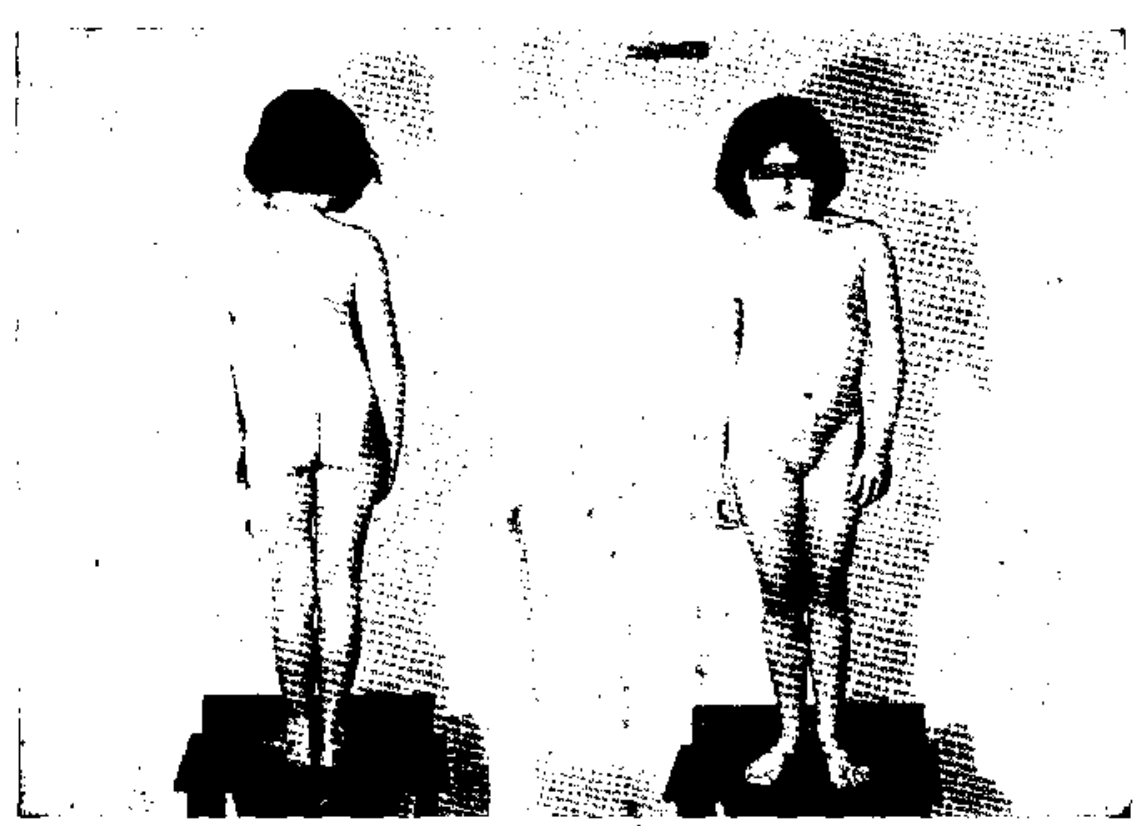

CASO N. 9.-O. G. Rosgravación por abundono ds ta cura gimnústica. 


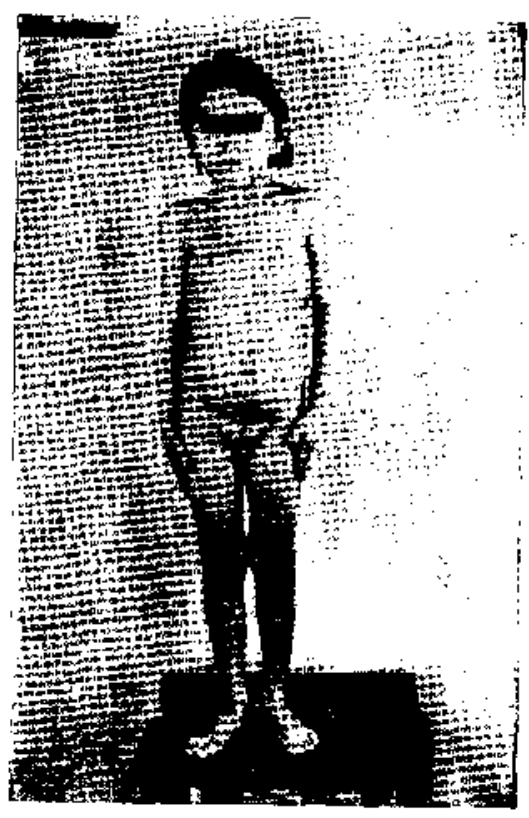

CASO N.: 10-N. Y. Antes de la cura kinésicz.

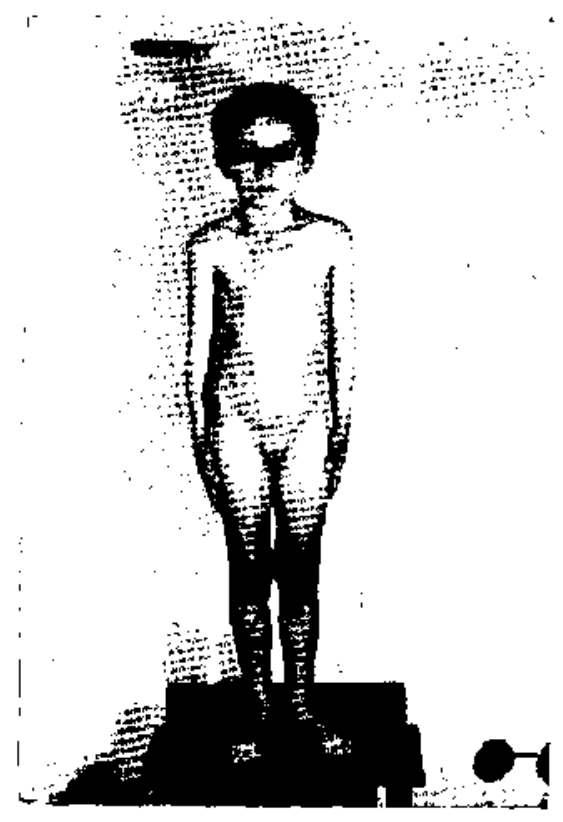

Después de la cuta kinésica.

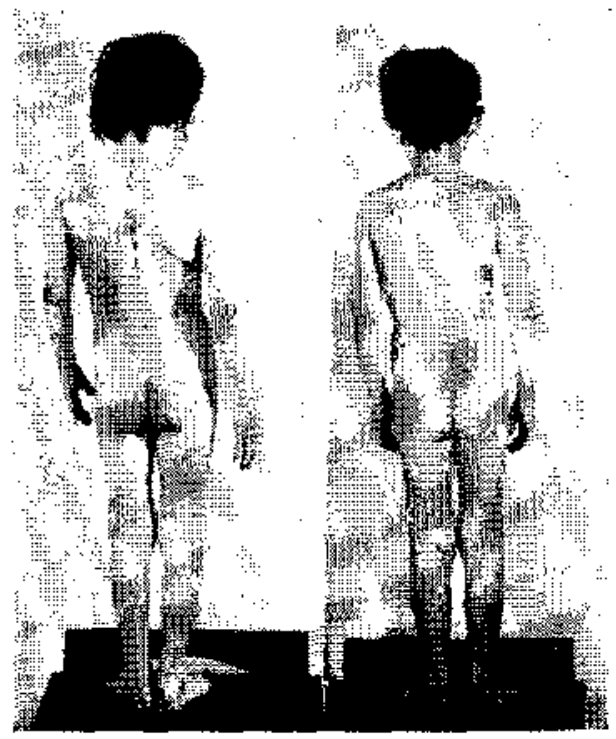

CASO N. 10.-N. Y. Después de la cura Antes de la cara kinésica. kinésica. 

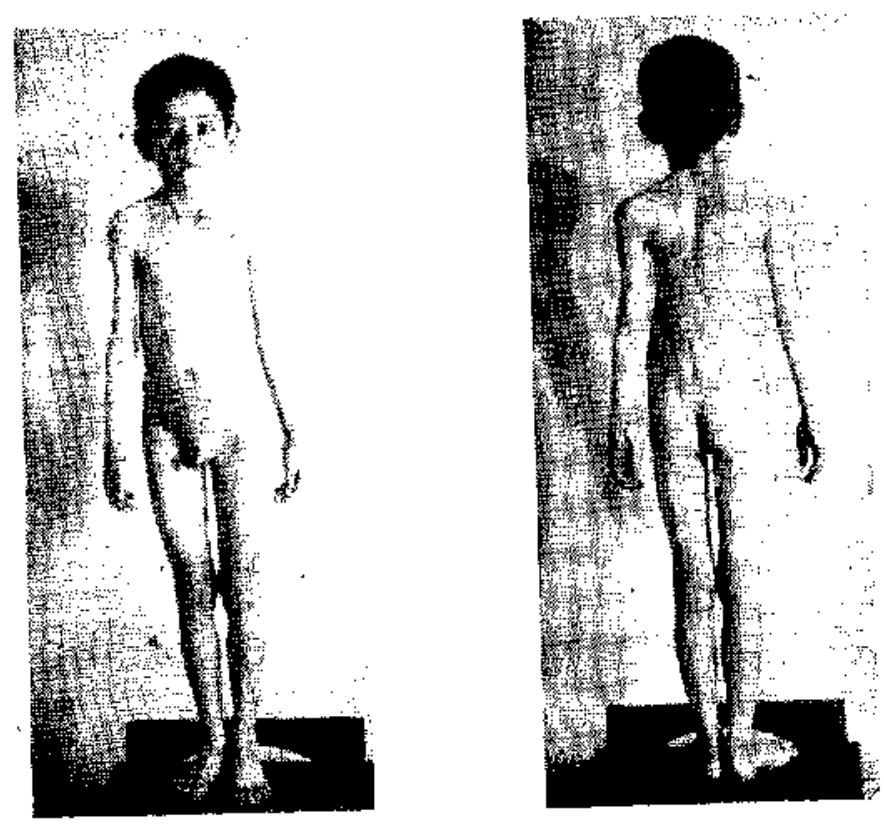

CA50 N"II. 
ritía et 25 de octubre de 1941 para reinitiar la gimnasia, que ptactita solamente durante 25 dias, no acudiendo despuśs. Se obtuvo correctión de I cm. en la corvadura y $1 \mathrm{~cm}$. en el desequilibrio. Examirada, por último, el 15 de abril de 1942, despaés de 3 meses de abzodono del tratimiento comprobanos que ha vaelto a un estado peor al anotado el 19 de agotto de 1941 . retrocediendo en la mejoría alcanzada.

CASO 10. - N. J.. 7 zños. Mujzr.

Ingresa al Servicio de Ciragía del Hospital Arriarán en raszo de 1941 . por nu empiema pleural crónico derecho, operado a mayo de 1940. No bay dutos anteriores.

Vista por nosotros el 3 de julio de $19+1$. encontramos una escoliosis dorsal izquierda de $1 \frac{1}{2}$ cm. con un desequilibrio de $1 \frac{1}{2} \mathrm{~cm}$. Y nna elevs. ción del omóplato izquierdo de 2 cms. Depresión en la región antero-superios del hemitórax izquierdo. Perímetro hemitónax derecho de $241 / 2$ cms.

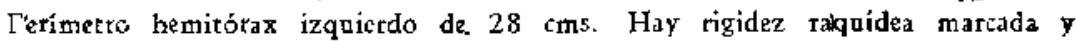
falta de elevación de las costillis derecha durante la inspiración. Mal estado get nera!. Desnutrición. Fiebre discreta (con alternativas de altas y bajas), Sapuración más o menos continua con ligeros cambios.

Inicia su cura de ejercicios en julio de 1941. con narnerosas incerrupciones a causa dz la fiebre y supuración, alcanzando, hasta. el 13 de felrtero de 1942, un total de 59 sesicnes.

Examinada por nosotros al 13 d: abril dz 1942, comprobamos que flexibilidad raquidea ba aumentado bazta sobrepasar la habitual en chicas de su miema edad; que hay juego cnstal infetior daranle la inspiración: que in escoliosis se ha becho casi imperceptible. como pued? verse en la fotografia, ranque la depresión de la región antero-supariot del bemitórax derecho pit siste. El perimetro del bimitóax detecho es de 24 cons, y el izquizrdo. de 20. Ji estado general es mejot. I.a fístula torácica se ha reduido considerblemente, pero te manticne ín. .

CASO I1. - R. V., 12 jños. Hombr?.

No $E$ conocen anticedentes.

$A \operatorname{los} 6$ años de edad (agosto de 1936). empicma irequierdo post.pnzarócócico a pneumecocos ripo II. Algunos dias despoés, pleurotonia con xesección costal en el Servicio de Citugia del Hospital Arriarán. dejándos tuto de Delber. Dos meszs más tätde, persiste la fistala, apreciárdose gràn retracción dei hemitótax, y paquiplzuritis total según la radiografía. Cuntinúa swpurando. retenienco a vetes. basta el 4 d? febreto de 1938. ́poca en que se practica una toracoplastía de 6 costillas, dasde li. $44^{*}$ a la $100^{*}$. Sigazsi un post-operatorio satisfactorio; piro pesciscen fístulas y suparación crónica. El 14 de octubre de 1938. Simpieza a cucharilla. Continúa. sin embatgo, supurando con alternativas. llegando a cerrar la fistula en una oportunidad. Sigaz un trntamiento kinésico irtegalar $y$ discontinuo, desde julio da 1941 en el 
Policlinico del Servicio, llevando hasta la fecha en que lo vemos (23 de abril) un total de 105 sesiones.

Presenta una escoliosis dorsal superior derecha de $21 / 2 \mathrm{cms}$, con un des. equilibrio igual. Muestra una elevación del omóplato derecho de $3 \mathrm{cms.,} \mathrm{is-}$ tanco sa borde espinal alejado en 7 cmis. de la línea media, en tanto que el izagierdo presenta un ángalo inferior sólo $21 \mathrm{~cm}$. de la línea de las apófisis espinosas y su ángulo superointerno, a $4 \mathrm{cms}$. ( $\mathrm{S}_{\mathrm{i}}$ en este caso hiciéramos la medición según el método de bacer pasar el bilo a plomo por la apófisis espinosa de la $\vec{z}$ cervical o prominentz, tendríamos, en vez de una escoliosis dorsa! superior, ana escoliosis dorsolumbar izquierda de $2 \frac{1}{2} \mathrm{cms}$ ). El perimetro exteno de! hemitórax derccho es de 29 cms. y el del izquierdo, 13. Dutante la inspiración éste se mantiene en 18 y sólo el derecho aumenta, basta 31 cms. Hay una fístula a rivel de la linea mamilar, a 3 sms, por debajo dệ mamelón. 